Article

\title{
Implementation of a Resonant Converter with Topology Morphing to Achieve Bidirectional Power Flow
}

\author{
Bor-Ren Lin
}

Citation: Lin, B.-R. Implementation of a Resonant Converter with Topology Morphing to Achieve Bidirectional Power Flow. Energies 2021, 14, 5186. https://doi.org/ $10.3390 /$ en14165186

Academic Editor: Waqar Uddin

Received: 22 July 2021

Accepted: 20 August 2021

Published: 22 August 2021

Publisher's Note: MDPI stays neutral with regard to jurisdictional claims in published maps and institutional affiliations.

Copyright: (C) 2021 by the author. Licensee MDPI, Basel, Switzerland. This article is an open access article distributed under the terms and conditions of the Creative Commons Attribution (CC BY) license (https:/ / creativecommons.org/licenses/by/ $4.0 /)$.
Department of Electrical Engineering, National Yunlin University of Science and Technology, Yunlin 640, Taiwan; linbr@yuntech.edu.tw

\begin{abstract}
A DC converter with the benefits of reverse power capability, less switching loss and wide voltage operation is presented and implemented for wide input voltage applications such as fuel cell energy, photovoltaic (PV) system and DC wind power. Two full bridge resonant circuits are used in the presented converter to achieve bidirectional power flow capability and reduce switching losses on active devices. To overcome the wide input DC voltage variation problem for fuel cell energy and PV solar panel, the topology morphing between the half bridge circuit and full bridge circuit is adopted on the primary side to obtain low (or high) voltage gain under a high (or low) input voltage condition. Therefore, the stable DC voltage is controlled at the load side by using the variable switching frequency modulation. The studied hybrid CLLC converter is tested by a $1 \mathrm{~kW}$ prototype and the performance is verified and confirmed by experiments.
\end{abstract}

Keywords: variable switching frequency; hybrid CLLC converter; wide DC input voltage

\section{Introduction}

DC and AC renewable power conversions with power converters [1,2] have been studied and presented to lessen the effect of global warming. For DC renewable power such as DC wind generators, photovoltaic (PV) solar panels and fuel cell stacks, the output voltage of these renewable clean energy sources is unstable and related to the wind speed and light intensity. Energy storage units [3] are required to save energy from the renewable energy or restore energy to the output load. Between the renewable power and storage components, bidirectional power converters are needed to achieve bidirectional power operation. Bidirectional converters have been presented and used in electric vehicle systems [4] or energy storage systems based on battery stacks. A multi-input transformercoupled Half bridge bidirectional DC converter was implemented in $[5,6]$ for household applications. Three power converters are used in this circuit topology to implement a $500 \mathrm{~W}$ prototype circuit. The main drawback is high component counts. In [7], the possible circuit topologies for electric vehicle applications are presented. The buck-boost DC converter is used between high voltage battery stacks and low voltage battery to achieve battery charge and discharge. In [8], a three-input boost converter without electric isolation was proposed in hybrid electric vehicle applications. The three ports of this DC/DC converter are the PV panel terminal, fuel cell terminal and battery stacks. Battery stacks can be charged from either a PV panel or a fuel cell. In [9], a half bridge converter with the pulsewidth modulation plus phase-shift control was presented to achieve bidirectional power operation. However, this circuit topology is a two-stage DC/DC converter. The main drawbacks are the high circuit counts and low efficiency. A dual active bridge converter with two half bridge circuits [10] or a full bridge circuit was proposed in [11,12] to achieve bidirectional power flow capability. Two control variables, phase-shift and duty cycle, are used to control the power flow. Thus, the control algorithm of this circuit topology is a little more complicated than the other bidirectional DC converters with only duty cycle control. Bidirectional resonant converters with two half bridge circuits were presented in [13] to achieve bidirectional power operation for electric vehicle applications. The 
primary and secondary sides of the isolated transformer are symmetric to ensure that the voltage transfer functions for both the forward and backward power operations are similar. In $[12,14]$, the full bridge based bidirectional resonant converters were presented for DC power distribution. The bidirectional resonant converters are easy to implement by using the analog or digital control algorithm to realize a voltage step-down or step-up operation. However, the drawback of the bidirectional resonant converters in [12-14] is the limit or narrow input (or output) voltage range operation.

A new resonant converter is studied and presented to realize wide input voltage operation, low switching loss and bidirectional power flow operation. Symmetric resonant circuits are adopted in the proposed circuit to realize the forward and reverse power operations. The variable frequency control is selected to generate the switching signals of power switches and the equivalent resonant circuit is controlled under an inductive load characteristic. Therefore, the active switches are turned on under zero voltage to reduce switching loss on power semiconductors. For forward power operation, the power switches on the high voltage side are operated as active devices to regulate the load voltage and the power switches on the low voltage side are operated as the synchronous switches. For reverse power operation, the active switches on the low voltage side are operated as active switches and the active switches on the high voltage side are active as synchronous switches. In order to overcome the limit voltage range problem on conventional resonant converters, the primary-side resonant circuit is operated as the half bridge (or full bridge) circuit structure to obtain low (or high) voltage gain according to input voltage range. Therefore, the proposed converter can be operated within a wide voltage operation. The adopted bidirectional resonant converter can be used in renewable power conversion with a wide voltage variation characteristic such as DC wind power, fuel cell power, solar power and a battery charger/discharger system. In Section 2, the circuit structure of the developed circuit is discussed. In Section 3, the circuit operations are presented. In Section 4, the circuit characteristics of the presented circuit are analyzed. The circuit components and experiments are derived and presented in Section 5 to demonstrate the performance of the studied circuit. A conclusion of the proposed circuit is presented in Section 6.

\section{Circuit Schematic of the Developed Converter}

Figure 1 gives the circuit blocks of a conventional bidirectional battery charger between high voltage Li-ion battery stacks and low voltage Li-ion battery stacks in electric vehicle applications. The voltage step-up and step-down DC converters are needed to achieve bidirectional power flow control. The possible voltage step-up and step-down converters are full bridge converters, as shown in Figure $2 \mathrm{a}$, and resonant converters with a half bridge circuit, in Figure 2b, or a full bridge circuit, in Figure 2c. These circuit topologies have high circuit efficiency and low switching losses. Resonant converters are much more attractive due to their high efficiency and fewer circuit components by using the variable switching frequency modulation. Figure 3 a gives the equivalent circuit of a resonant tank in a resonant converter. $V_{i n, F}$ and $n V_{o, F}$ are the root-mean-square values of the input and output voltages at the fundamental switching frequency. $R_{a c}$ is the ac equivalent load resistor on the transformer primary side. Due to the variable switching control, the relationship between voltage gain $M_{a c}$ and switching frequency index $F=f_{s w} / f_{r}$ (where $f_{s w}$ and $f_{r}$ are the switching frequency and resonant frequency) is provided in Figure $3 \mathrm{~b}$. The voltage gain $M_{a c}$ is related to the load condition $Q$ and switching frequency index $F$. If the switching frequency $f_{s w}>$ resonant frequency $f_{r}$, i.e., $F>1$, the power switches, such as $S_{1}$ and $S_{2}$, are tuned on at zero voltage and the converter has less magnetzing current loss. If the resonant converter is perated at $f_{s w}<f_{r}$, i.e., $F<1$, then the rectifier diodes are turned off at zero current and power switches are turned on at zero voltage. However, the resonant converter operated at low switching frequency will result in more magnetizing current loss. 


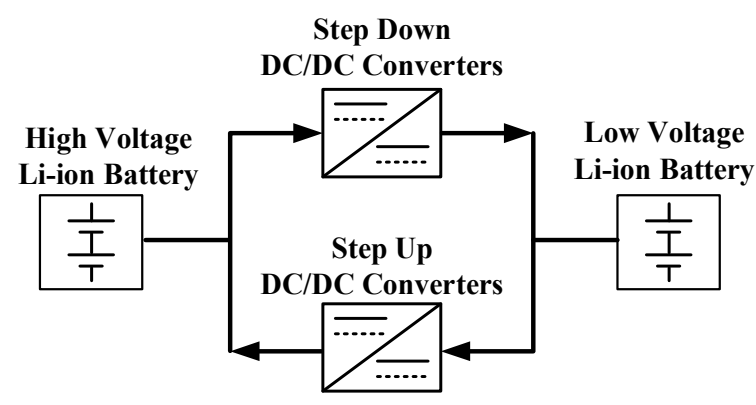

Figure 1. Circuit blocks of conventional bidirectional converter.

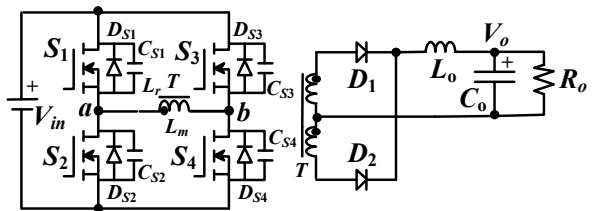

(a)

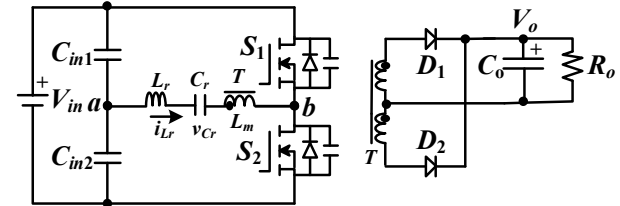

(b)

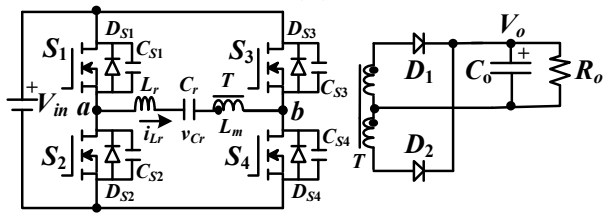

(c)

Figure 2. Possible circuit structures used in battery charger: (a) full bridge PWM converter, (b) half bridge resonant converter, (c) full bridge resonant converter.

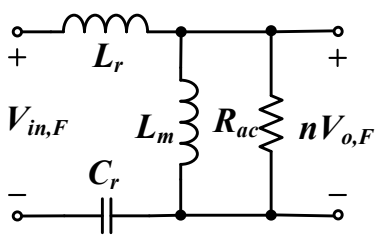

(a)

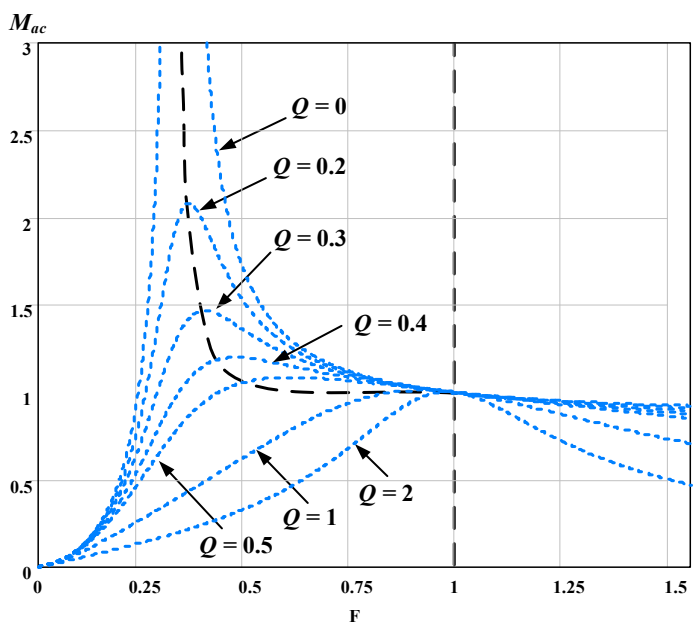

(b)

Figure 3. Resoant tank of resonant converter: (a) equivalent circuit, (b) voltage gain.

The disadvantages of the unidirectional DC converters for a battery charger are the required step-up and step-down circuits to ensure that more circuit components are needed. The conventional bidirectional converters with a high circuit efficiency are the dual active bridge (DAB) converter (Figure 4a) and the CLLC resonant converter shown in Figure $4 b$,c. Two full bridge PWM circuits are used in the DAB converter. By controlling the leading or lagging angle between the leg voltages $V_{a b}$ and $V_{c d}$ in Figure 4 a, power can be transferred from $V_{\text {in }}$ to $V_{b a t}$ or from $V_{b a t}$ to $V_{i n}$. However, the control algorithm of the DAB converter is more complicated than the CLLC resonant converter to achieve bidirectional power conversion. Figure $4 b$,c give the CLLC resonant converters with a symmetric half bridge circuit structure and a symmetric full bridge circuit structure, respectively. When power 
is transferred from $V_{\text {in }}$ to $V_{o}$ in Figure $4 \mathrm{~b}, S_{1}$ and $S_{2}$ on the left-hand side are operated as active switches with variable switching frequency modulation and $S_{3}$ and $S_{4}$ on the right-hand side are operated as synchronous switches. When power is transferred from $V_{o}$ (right-hand side) to $V_{\text {in }}$ (left-hand side) in Figure $4 \mathrm{~b}, S_{3}$ and $S_{4}$ are activated as power switches and $S_{1}$ and $S_{2}$ are activated as synchronous switches.

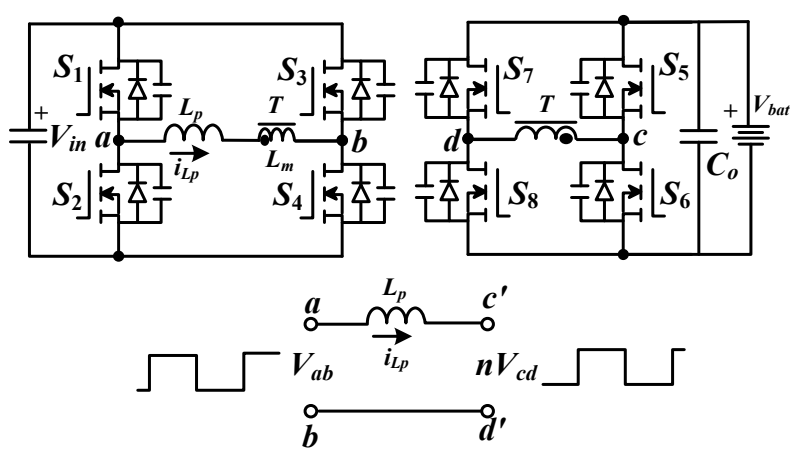

(a)

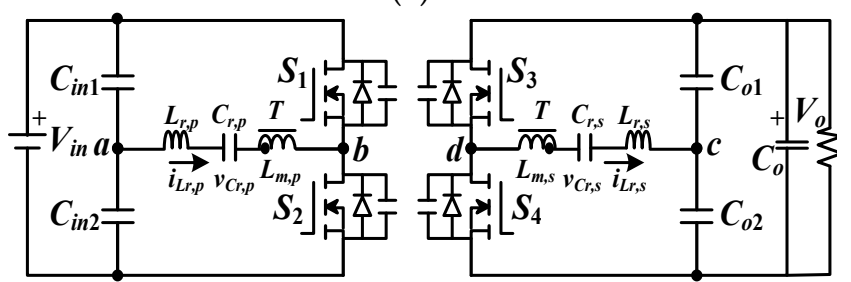

(b)

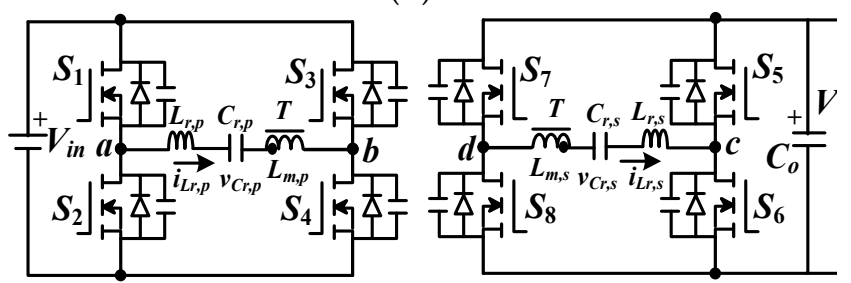

(c)

Figure 4. Bidirectional DC/DC converters: (a) dual active bridge structure with pulse-width modulation, (b) resonant circuit with half bridge structure, (c) resonant circuit with full bridge structure.

Figure 5a shows the circuit diagram of the presented circuit with the advantages of a soft switching operation of active switches, bidirectional power flow operation and wide input voltage operation. A full bridge resonant circuit is used on the left-hand (high voltage) side. Similarly, a full bridge circuit with $Q_{1} \sim Q_{4}$ devices is adopted on the output side. Figure $5 \mathrm{~b}$ shows the equivalent circuit when the converter is operated at a forward power operation when $V_{i n}$ is in a low voltage range. Switch $S_{5}$ is off and the full bridge resonant circuit with switches $S_{1} \sim S_{4}$ is operated on the left-hand side (input side). Figure $5 c$ gives the equivalent circuit when $V_{\text {in }}$ is in a high voltage range under a forward power flow operation. Switch $S_{5}$ is on and $S_{3}$ and $S_{4}$ are off. The half bridge resonant circuit with switches $S_{1}$ and $S_{2}$ is controlled by using the variable switching frequency modulation to control the power flow from $V_{\text {in }}$ to $V_{o}$. For a forward power transfer operation, $Q_{1} \sim Q_{4}$ on the output side are operated as the synchronous switches. If the proposed converter is operated as the reverse power transfer from $V_{o}$ to $V_{i n}$ as shown in Figure $5 \mathrm{~d}, Q_{1} \sim Q_{4}$ are controlled by using a variable switching frequency modulation and a voltage doubler rectifier with synchronous switches $S_{1}$ and $S_{2}$ being used on lefthand side of the proposed converter. Then, the voltage $V_{\text {in }}$ is controlled at the desired voltage value under a high voltage range. Based on the above three operating circuits, the studied resonant converter can achieve the bidirectional power flow and wide voltage range operation compared to the conventional bidirectional converters shown in Figure 4. 
Table 1 gives the comparisons between the proposed bidirectional resonant converter, conventional CLLC resonant converter and dual active bridge converter. One can observe that the proposed converter has two more power switches compared to the full bridge CLLC converter and the dual active bridge converter. However, the proposed converter has a much wider input voltage range than the other circuit topologies in Table 1.

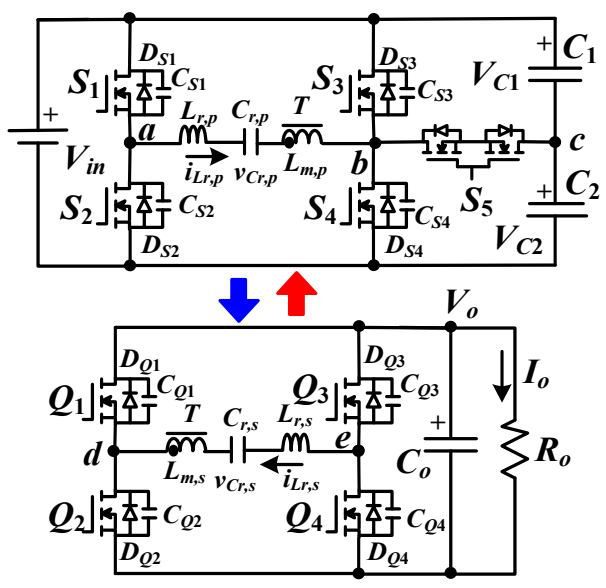

(a)

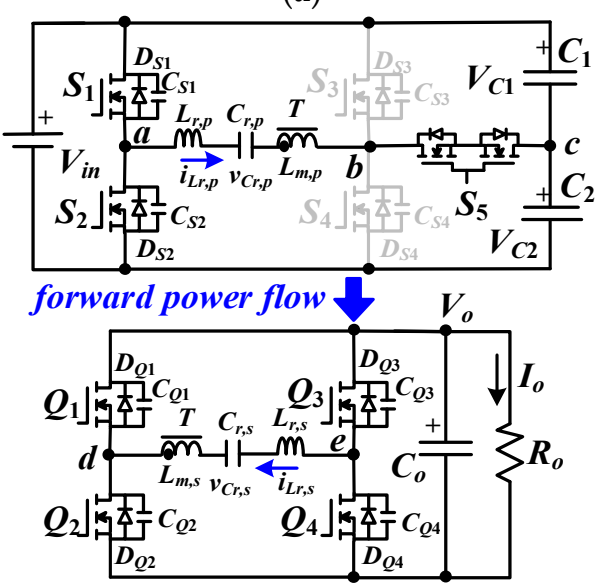

(c)

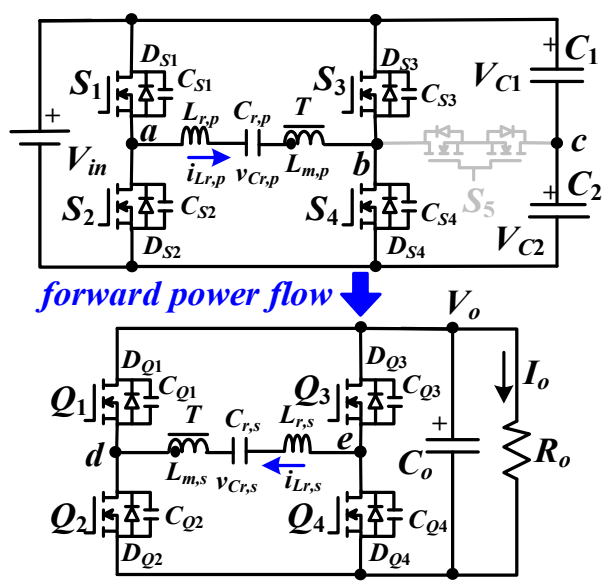

(b)

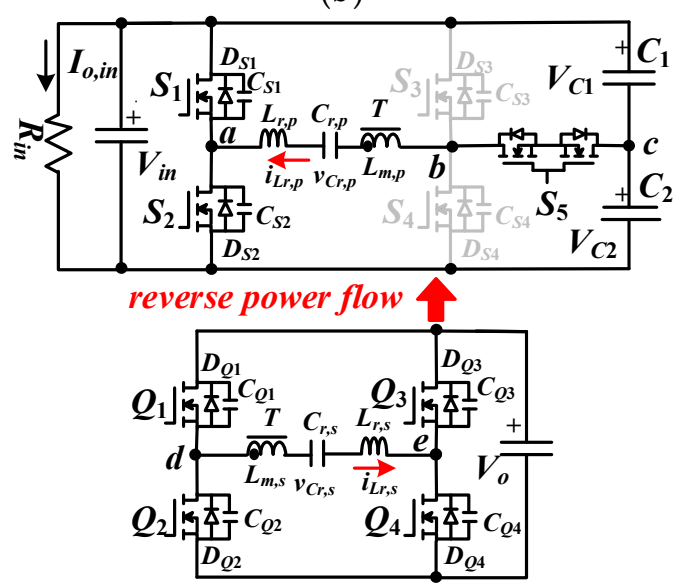

(d)

Figure 5. Proposed bidirectional resonant converter: (a) circuit configuration, (b) equivalent circuit under forward power flow and low input voltage range, (c) equivalent circuit under forward power flow and high input voltage range, (d) equivalent circuit under reverse power flow operation.

Table 1. Comparisons between the proposed bidirectional resonant converter, conventional CLLC resonant converter and dual active bridge converter.

\begin{tabular}{ccccc}
\hline Topology & $\begin{array}{c}\text { Power } \\
\text { Switches }\end{array}$ & $\begin{array}{c}\text { Split dc } \\
\text { Capacitor }\end{array}$ & $\begin{array}{c}\text { Resonant } \\
\text { Components }\end{array}$ & $\begin{array}{c}\text { Voltage Range, } \\
\text { Power Rating }\end{array}$ \\
\hline $\begin{array}{c}\text { Proposed } \\
\text { converter }\end{array}$ & 10 & 2 & 4 & $\begin{array}{l}V_{\text {in }}=100-400 \mathrm{~V}, V_{o}=48 \mathrm{~V}, \\
P_{o}=1 \mathrm{~kW}\end{array}$ \\
\hline $\begin{array}{c}\text { Half bridge } \\
\text { CLLC converter }\end{array}$ & 4 & 4 & 4 & $\begin{array}{l}V_{\text {in }}=400-600 \mathrm{~V}, \\
V_{o}=300-450 \mathrm{~V}, P_{o}=3.3 \mathrm{~kW} \\
\text { in }[13]\end{array}$ \\
\hline $\begin{array}{c}\text { Full bridge } \\
\text { CLLC converter }\end{array}$ & 8 & 0 & 4 & $\begin{array}{l}V_{\text {in }}=382-408 \mathrm{~V}, V_{o}=50 \mathrm{~V}, \\
P_{o}=400 \mathrm{~W} \text { in }[12]\end{array}$ \\
\hline $\begin{array}{c}\text { Dual active } \\
\text { bridge converter }\end{array}$ & 8 & 0 & 1 & $\begin{array}{l}V_{\text {in }}=600 \mathrm{~V}, V_{o}=300-450 \mathrm{~V}, \\
P_{o}=10 \mathrm{~kW} \text { in }[12]\end{array}$ \\
\hline
\end{tabular}




\section{Circuit Operation}

\subsection{Forward Power Operation under Low Input Voltage Range}

If the proposed circuit is controlled at a low input voltage range and forward power operation, the electric power is flowed from $V_{\text {in }}$ terminal to $V_{o}$ terminal. Power switch $S_{5}$ is off, $S_{1} \sim S_{4}$ are triggered with variable switching frequency modulation and $Q_{1} \sim Q_{4}$ are controlled as synchronous switches. Since $S_{1} \sim S_{4}$ all have a 0.5 duty cycle, the leg voltage $V_{a b}$ is a square voltage waveform. The PWM signals are shown in Figure 6a. The converter has six or four operating modes in every switching cycle under $f_{s w}$ (switching frequency) less or greater than $f_{r}$ (resonant frequency). Figure $6 \mathrm{~b}-\mathrm{g}$ illustrate the equivalent circuits. For the system analysis, the resonant components are assumed as $L_{r, p}=n^{2} L_{r, s}$ and $C_{r, p}=C_{r, s} / n^{2}$, where $n=n_{p} / n_{s}$ to have the same resonant frequency for both the primary and secondary sides.

Mode 1 [ $t_{0} \sim t_{1}$ ]: At $t_{0}, S_{1}, S_{4}, Q_{1}$ and $Q_{4}$ are on. The current $i_{L r, p}$ flows through $S_{1}, L_{r, p}$, $C_{r, p}, T$ and $S_{4}$. The current $i_{L r, s}$ flows through $Q_{4}, L_{r, s}, C_{r, s}, T, Q_{1}$ and $C_{0}$. Therefore, the leg voltages $V_{a b}=V_{i n}$ and $V_{d e}=V_{o}$. The resonant frequency is about $f_{r}=1 /\left(2 \pi \sqrt{L_{r, p} C_{r, p}}\right)$. The primary and secondary currents, $i_{L r, p}$ and $i_{L r, s}$, increase.

Mode $2\left[t_{1} \sim t_{2}\right]$ : For $f_{r}>f_{s w}$ (i.e., $F<1$ ), the secondary side current, $i_{r, s}$, is decreased to 0 at $t_{1}$. Then, $Q_{1}$ and $Q_{4}$ turn off. The resonant frequency becomes $f_{p}=1 /\left(2 \pi \sqrt{\left(L_{r, p}+L_{m, p}\right) C_{r, p}}\right)$ in mode two.

Mode $3\left[t_{2} \sim t_{3}\right]$ : At $t_{2}, S_{1}$ and $S_{4}$ turn off and $i_{L r, p}$ discharges $C_{S 2}$ and $C_{S 3}$. If Equation (1) is established, $v_{C S 2}$ and $v_{C S 3}$ are $0 \mathrm{~V}$ at $t_{3}$.

$$
i_{L m, p, p k} \geq V_{i n} \sqrt{\frac{2 C_{S, e q}}{L_{r, p}}}
$$

where $C_{S, e q}=C_{S 1}=C_{S 2}=C_{S 3}=C_{S 4}$ and $i_{L m, p, p k}$ is the peak value of $i_{L m, p}$.

Mode $4\left[t_{3} \sim t_{4}\right]$ : At $t_{3}, v_{C S 2}=v_{C S 3}=0$ and $D_{S 2}$ and $D_{S 3}$ are forward biased due to $i_{L r, p}>0$. In this mode, $S_{2}, S_{3}, Q_{2}$ and $Q_{3}$ are on. In this mode, $V_{a b}=-V_{i n}, V_{d e}=-V_{o}$ and $i_{L r, p}$ and $i_{L r, S}$ both decrease.

Mode $5\left[t_{4} \sim t_{5}\right]$ : At time $t_{4}, i_{L r, p}=i_{L m, p}$ and $i_{L r, s}=0$. Thus, the synchronous switches $Q_{3}$ and $Q_{2}$ are off. $C_{r, p}, L_{r, p}$ and $L_{m, p}$ are resonant.

Mode $6\left[t_{5} \sim T_{s w}+t_{0}\right]: S_{2}$ and $S_{3}$ turn off at $t_{5}$ and $i_{L r, p}$ will discharge $C_{S 1}$ and $C_{S 4}$. Since $C_{S 1} \sim C_{S 4}$ are much less than $C_{r, p}$, the discharge time in mode six is fast enough to be neglected in the system analysis. The one switching cycle is ended at time $T_{s w}+t_{0}$.

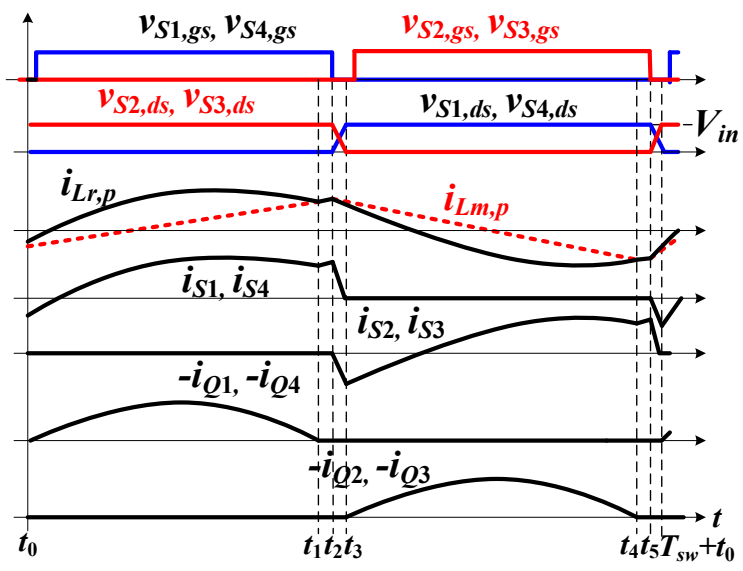

(a)

Figure 6. Cont. 
Energies 2021, 14, 5186

7 of 21

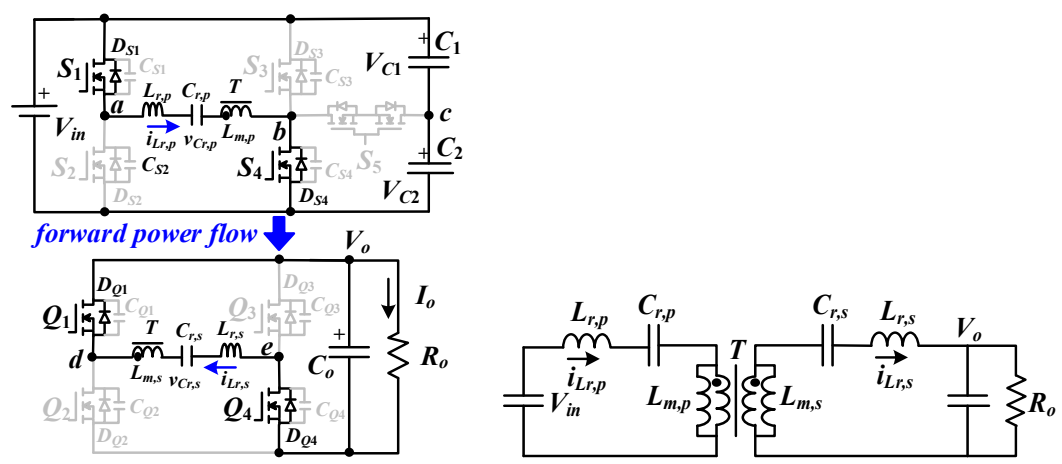

(b)

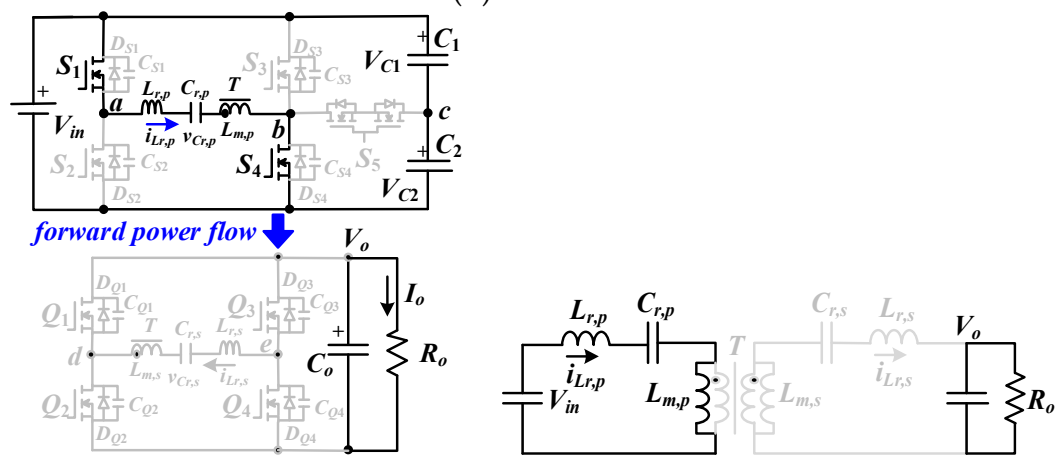

(c)

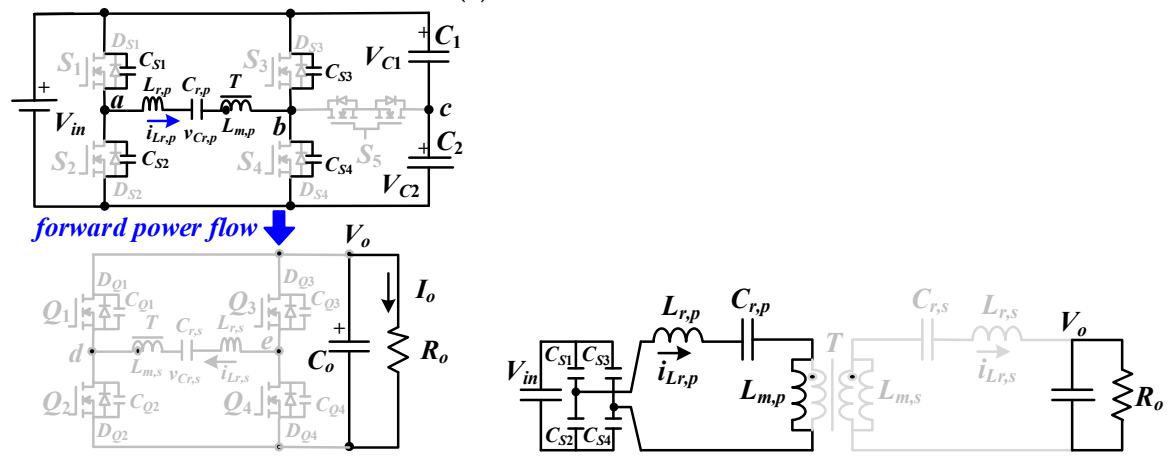

(d)
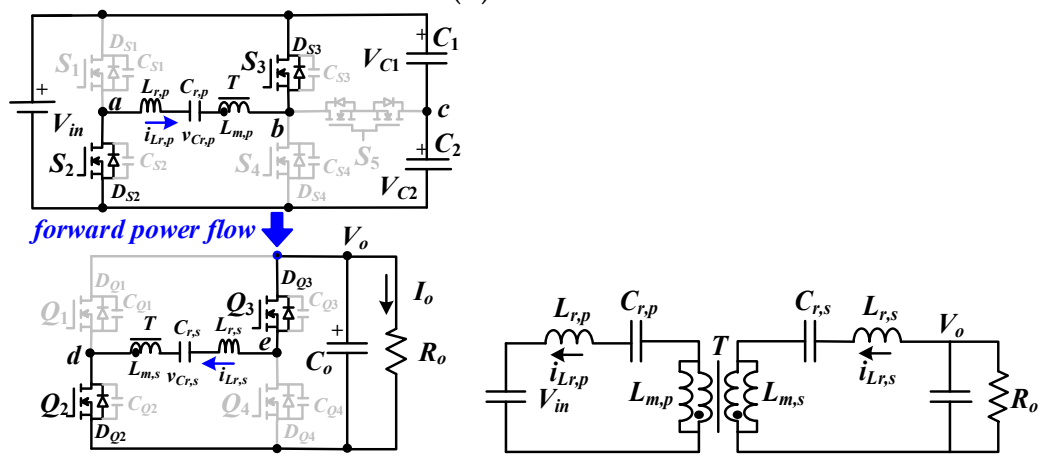

(e)

Figure 6. Cont. 

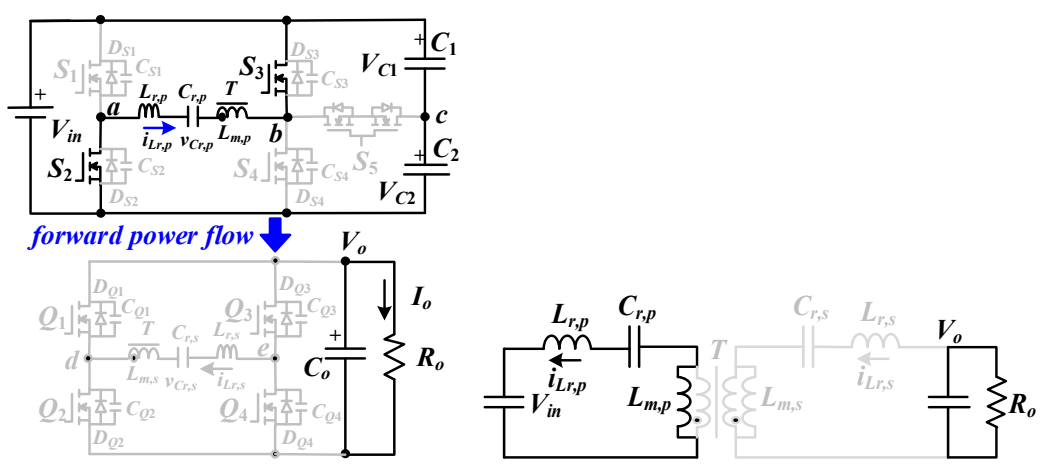

(f)
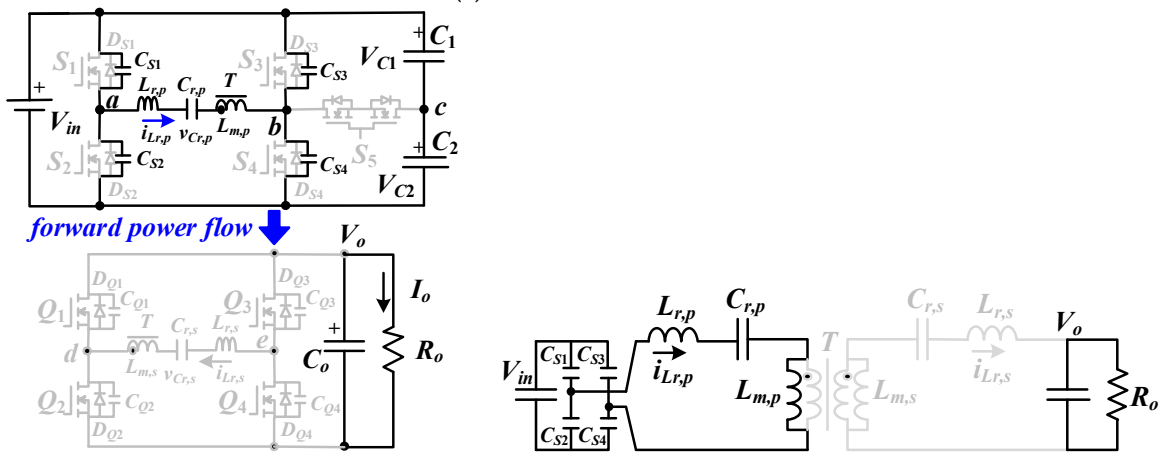

(g)

Figure 6. The corresponding mode circuits under forward power operation and low input voltage range: (a) PWM signals, (b) mode 1, (c) mode 2, (d) mode 3, (e) mode 4, (f) mode 5, (g) mode 6.

\subsection{Forward Power Operation under High Input Voltage Range}

If $V_{\text {in }}$ is in the high input voltage range, $S_{5}$ turns on and $S_{3}$ and $S_{4}$ are off (Figure 5c). The half bridge resonant circuit is operated on the left-hand side to obtain less voltage gain compared to the full bridge resonant circuit (Figure 5b). The half bridge resonant circuit in Figure $5 c$ has the same PWM signals and equivalent mode circuits as the full bridge resonant circuit in Figure 6. Therefore, the discussions of the circuit analysis for forward power flow operation and high input voltage range condition are neglected in this section.

\subsection{Reverse Power Operation}

Figure $5 \mathrm{~d}$ gives the circuit structure of the proposed converter operated as a reverse power flow condition from $V_{o}$ (load side) to $V_{\text {in }}$ (input side). Since the primary-side voltage $V_{\text {in }}$ is controlled at $400 \mathrm{~V}$ (in high voltage range) under reverse power operation, $S_{5}$ turns on and $S_{3}$ and $S_{4}$ are off. The full bridge resonant circuit with active switches $Q_{1} \sim Q_{4}$ are used and controlled on the right-hand side of the proposed circuit. The voltage doubler rectifier with synchronous switches $S_{1}$ and $S_{2}$ are used on the left-hand side. Figure 7 illustrates the PWM signals and mode circuits of the presented circuit under reverse power operation.

Mode 1 [ $\left.t_{0} \sim t_{1}\right]: v_{C Q 1}=v_{C Q 4}=0$ at $t_{0}$ and $i_{L r, S}$ will flow through the diodes $D_{Q 1}$ and $D_{Q 4}$ due to $i_{L r, S}<0$. Therefore, active devices $Q_{4}$ and $Q_{1}$ turn on under zero voltage and $V_{d e}=V_{o}$. Since $i_{L r, p}\left(t_{0}\right)>0$, synchronous switch $S_{1}$ is on and $V_{a c}=V_{i n}$.

Mode 2 [ $t_{1} \sim t_{\mathbf{2}}$ ]: $i_{r, p}=0$ at time $t_{1}$ and $S_{1}$ turns off. The components $L_{r, s}, L_{m, s}$ and $C_{r, s}$ are resonant on the right-hand side of the equivalent circuit.

Mode $3\left[t_{2} \sim t_{3}\right.$ ]: $Q_{1}$ and $Q_{4}$ turn off at time $t_{2}$ and $i_{L r, S}$ will discharge $C_{Q 2}$ and $C_{Q 3}$. $C_{Q 2}$ and $\mathrm{C}_{\mathrm{Q} 3}$ can be discharged to zero voltage if Equation (2) is satisfied.

$$
i_{L m, s, p k} \geq V_{o} \sqrt{\frac{2 C_{Q, e q}}{L_{r, s}}}
$$

where $C_{Q, e q}=C_{Q 1}=C_{Q 2}=C_{Q 3}=C_{Q 4}$ and $i_{L m, s, p k}$ is the peak value of $i_{L m, s}$. 
Mode $4\left[t_{3} \sim t_{4}\right]: v_{C Q 2}$ and $v_{C Q 3}$ are decreased to 0 at $t_{3} . D_{Q 2}$ and $D_{Q 3}$ are conducting due to $i_{L r, S}>0$. In mode four, active switches $Q_{2}, Q_{3}$ and synchronous switch $S_{2}$ are on. Therefore, $V_{d e}=-V_{o}$ and $V_{a c}=-V_{\text {in }}$.

Mode $5\left[t_{4} \sim t_{5}\right]: i_{L r, p}=0$ at $t_{4}$ and $S_{2}$ turns off. $C_{r, s}, L_{r, s}$ and $L_{m, s}$ are resonant.

Mode $6\left[t_{5} \sim T_{s w}+t_{0}\right]: Q_{2}$ and $Q_{3}$ turn off at $t_{5}$ and $i_{L r, S}$ discharges $C_{Q 1}$ and $C_{Q 4}$ due to $i_{L r, s}<0$. At $T_{s w}+t_{0}$, this switching cycle is completed.

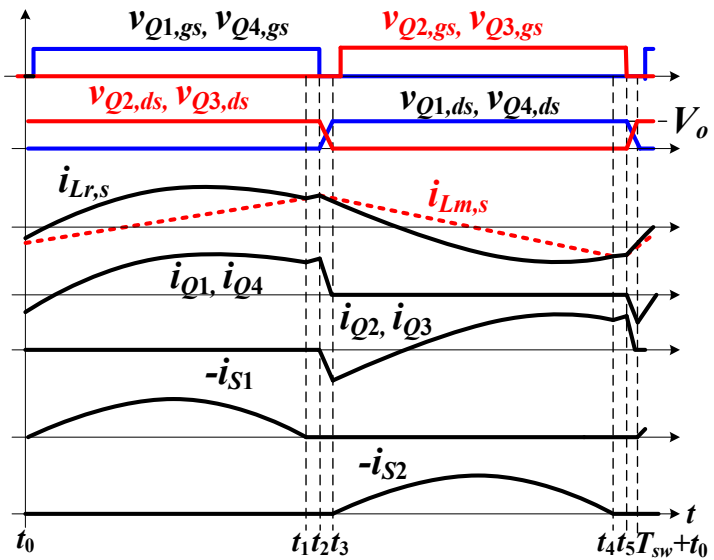

(a)
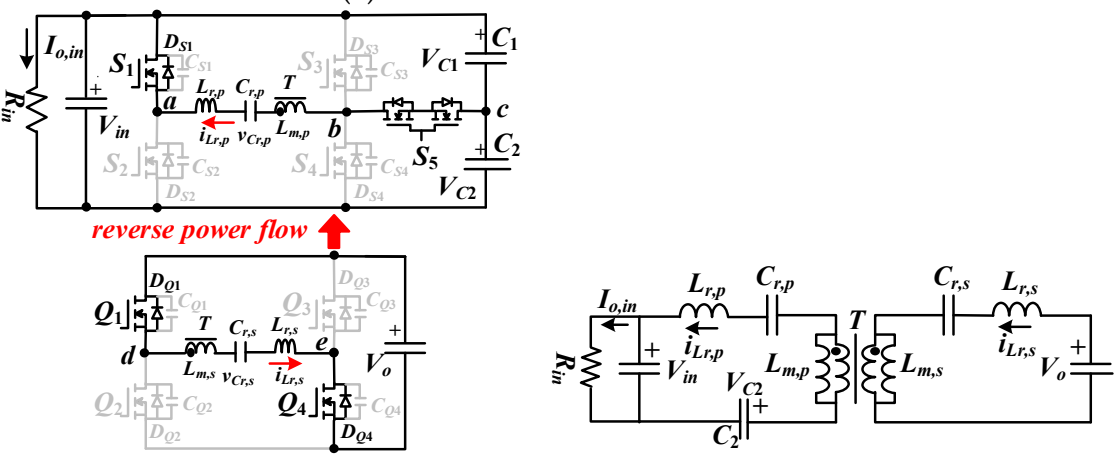

(b)

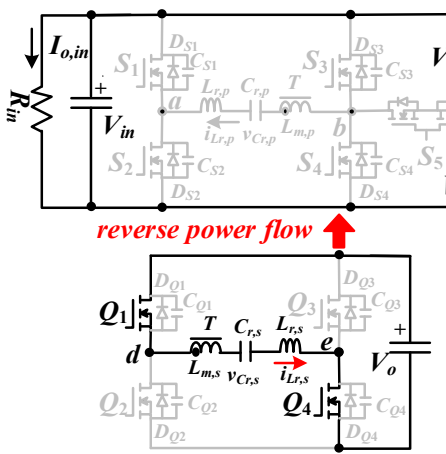

$+\frac{+}{=} C_{1}$

$V_{C 2}^{+}$

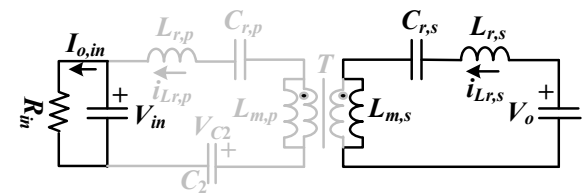

(c)

Figure 7. Cont. 

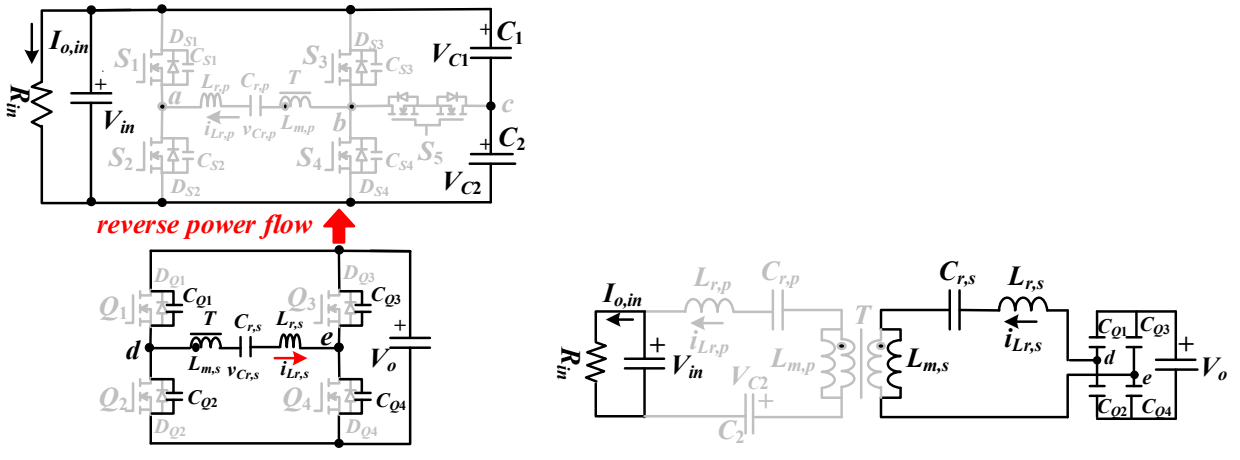

(d)
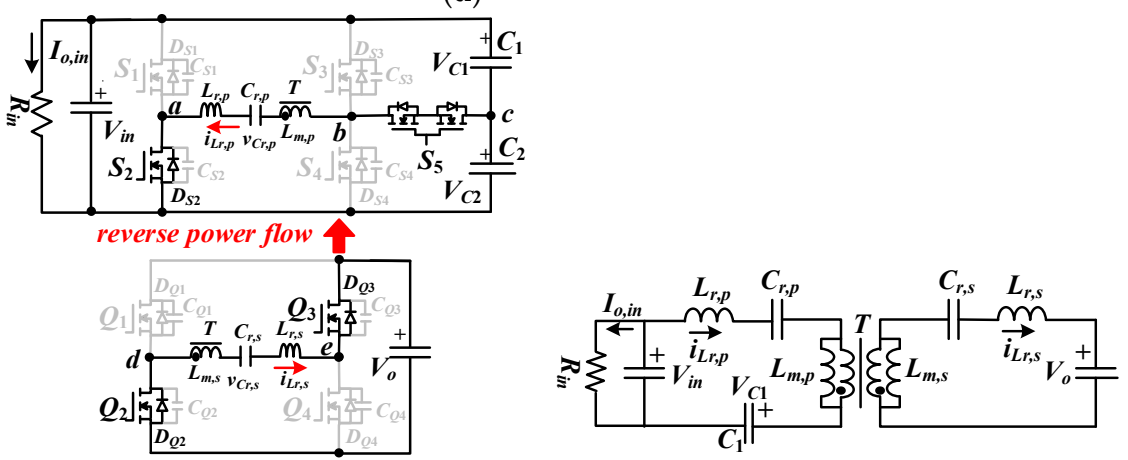

(e)
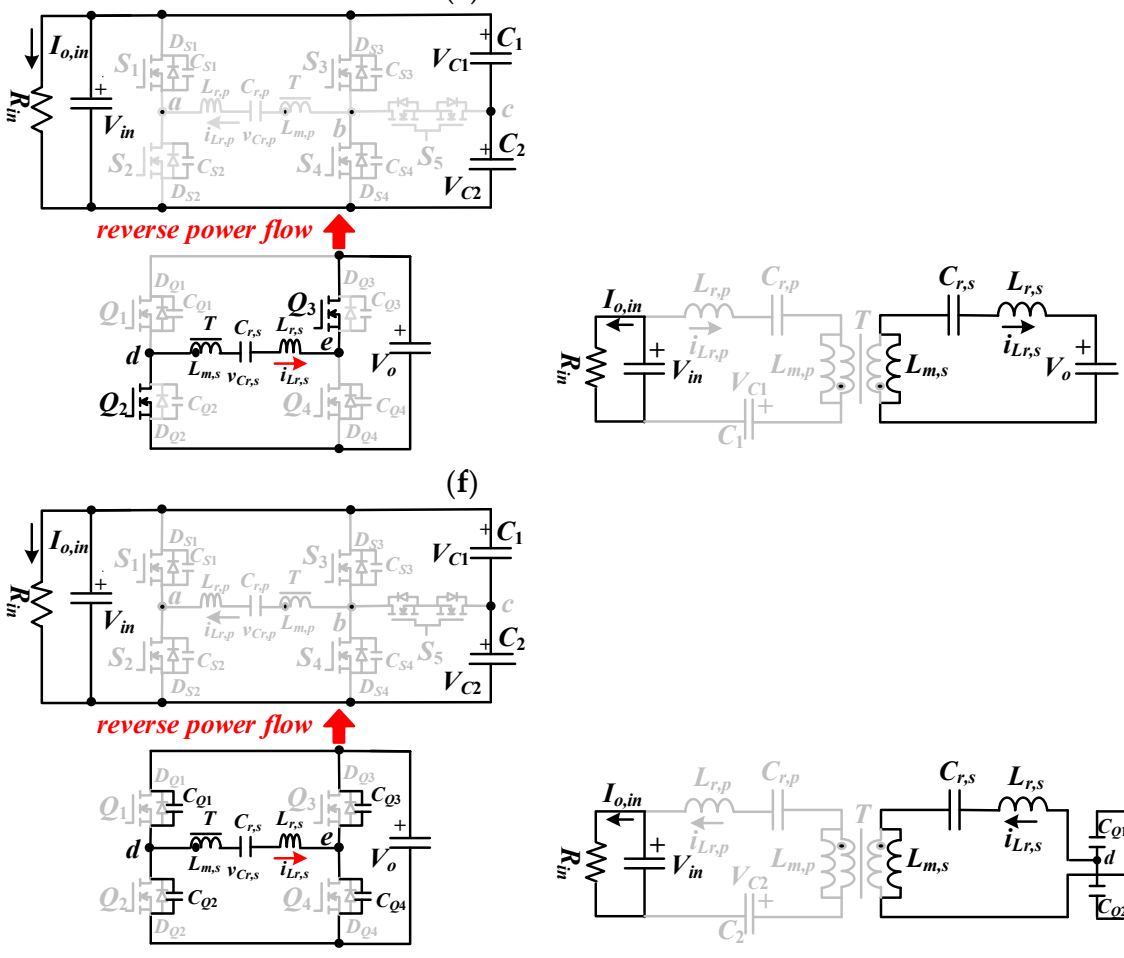

(g)

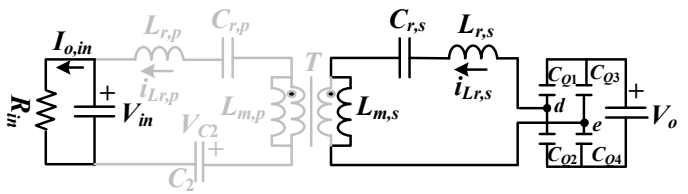

Figure 7. The corresponding mode circuits under reverse power operation: (a) PWM signals, (b) mode 1, (c) mode 2, (d) mode 3, (e) mode 4, (f) mode 5, (g) mode 6.

\section{Circuit Characteristics}

The active devices on the presented circuit are controlled with a variable switching frequency modulation. For the low voltage range, switch $S_{5}$ turns off and $S_{1}-S_{4}$ are operated as the full bridge resonant converter to have high voltage gain. For a high voltage range, $S_{3}$ and $S_{4}$ are off and $S_{1}, S_{2}$ and $S_{5}$ are operated as half bridge resonant converters 
to have less voltage gain. $Q_{1}-Q_{4}$ are operated as synchronous switches for the full bridge rectifier under forward power operation.

In Figure 8, the input and output terminals of the equivalent resonant circuit are square voltage waveforms. If the left-hand side (primary side) of the proposed converter is operated at full bridge or half bridge circuit, the leg voltage $V_{a b}= \pm V_{\text {in }}$ or $V_{a c}= \pm V_{\text {in }} / 2$ under forward power operation. Similarly, $V_{d e}= \pm V_{o}$ on the right-hand side (secondary side) of the presented circuit. The circuit characteristic of the studied circuit is based on the fundamental switching frequency analysis. The resonant tank for both forward and reverse power operations are shown in Figure 8. $R_{o, a c}$ and $R_{i n, a c}$ are the fundamental ac resistances for forward and reverse power operations, respectively.

$$
\begin{aligned}
& R_{o, a c}=\frac{8 n^{2} R_{o}}{\pi^{2}} \\
& R_{i n, a c}=\frac{2 R_{i n}}{\pi^{2} n^{2}}
\end{aligned}
$$

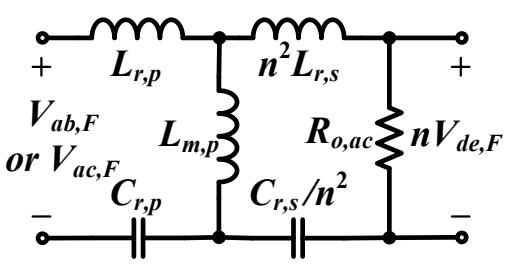

(a)

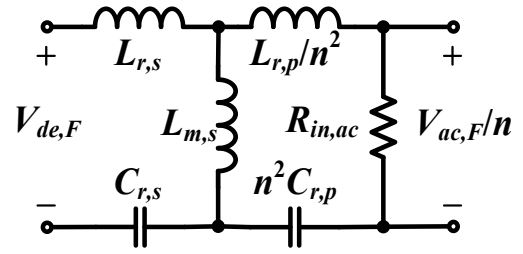

(b)

Figure 8. The resonant tank of the proposed converter at fundamental switching frequency: (a) forward power operation, (b) reverse power operation.

The fundamental root-mean-square leg voltage $V_{a b, F}$ is expressed in Equations (5) and (6) for full bridge resonant circuit and half bridge resonant circuit.

$$
\begin{aligned}
V_{a b, F} & =\frac{2 \sqrt{2} V_{i n}}{\pi} \\
V_{a c, F} & =\frac{\sqrt{2} V_{i n}}{\pi}
\end{aligned}
$$

Similar, the fundamental root-mean-square leg voltage $V_{d e, F}$ is expressed in Equation (7).

$$
V_{d e, F}=\frac{2 \sqrt{2} V_{o}}{\pi}
$$

The voltage transfer functions in Figure 8a under forward power operations are given in Equations (8) and (9) for a low and high input voltage range, respectively. The voltage transfer function in Figure 8b under reverse power operation is given in Equation (10).

$$
\begin{gathered}
M_{a c, F, L o w}(s)=\frac{s L_{m, p} / /\left(s n^{2} L_{r, s}+\frac{n^{2}}{s C_{r, s}}+R_{o, a c}\right)}{s L_{r, p}+\frac{1}{s C_{r, p}}+\left[s L_{m, p} / /\left(s n^{2} L_{r, s}+\frac{n^{2}}{s C_{r, s}}+R_{o, a c}\right)\right]} \times \frac{R_{o, a c}}{s n^{2} L_{r, s}+\frac{n^{2}}{s C_{r, s}}+R_{o, a c}} \\
M_{a c, F, H i g h}(s)=\frac{s L_{m, p} / /\left(s n^{2} L_{r, s}+\frac{n^{2}}{s C_{r, s}}+R_{o, a c}\right)}{s L_{r, p}+\frac{1}{s C_{r, p}}+\left[s L_{m, p} / /\left(s n^{2} L_{r, s}+\frac{n^{2}}{s C_{r, s}}+R_{o, a c}\right)\right]} \times \frac{R_{o, a c}}{s n^{2} L_{r, s}+\frac{n^{2}}{s C_{r, s}}+R_{o, a c}} \\
M_{a c, R}(s)=\frac{s L_{m, s} / /\left(s L_{r, p} / n^{2}+\frac{1}{s n^{2} C_{r, p}}+R_{i n, a c}\right)}{s L_{r, s}+\frac{1}{s C_{r, s}}+\left[s L_{m, s} / /\left(s L_{r, p} / n^{2}+\frac{1}{s n^{2} C_{r, p}}+R_{i n, a c}\right)\right]} \times \frac{R_{i n, a c}}{s L_{r, p} / n^{2}+\frac{1}{s n^{2} C_{r, p}}+R_{i n, a c}}
\end{gathered}
$$


From Equations (8)-(10), three voltage gains under three different circuit operations are expressed as follows:

$$
\begin{gathered}
\left|M_{a c, F, \text { Low }}(Q, F, K)\right|=\frac{n V_{o}}{V_{\text {in }}}=\frac{1}{\sqrt{\left[1+\frac{1}{K}-\frac{1}{K F^{2}}\right]^{2}+Q^{2}\left[F\left(2+\frac{1}{K}\right)-\frac{1}{F}\left(2+\frac{2}{K}-\frac{1}{K F^{2}}\right)\right]^{2}}} \\
\left|M_{a c, F, H i g h}(Q, F, K)\right|=\frac{2 n V_{o}}{V_{i n}}=\frac{1}{\sqrt{\left[1+\frac{1}{K}-\frac{1}{K F^{2}}\right]^{2}+Q^{2}\left[F\left(2+\frac{1}{K}\right)-\frac{1}{F}\left(2+\frac{2}{K}-\frac{1}{K F^{2}}\right)\right]^{2}}} \\
\left|M_{a c, R}\left(Q^{\prime}, F^{\prime}, K^{\prime}\right)\right|=\frac{V_{\text {in }}}{2 n V_{o}}=\frac{1}{\sqrt{\left[1+\frac{1}{K^{\prime}}-\frac{1}{K \prime F I^{2}}\right]^{2}+Q^{\prime 2}\left[F \prime\left(2+\frac{1}{K \prime}\right)-\frac{1}{F \prime}\left(2+\frac{2}{K \prime}-\frac{1}{K \prime F F^{\prime}}\right)\right]^{2}}}
\end{gathered}
$$

where $Q=\sqrt{L_{r, p} / C_{r, p}} / R_{o, a c}, Q^{\prime}=\sqrt{L_{r, s} / C_{r, s}} / R_{i n, a c}, K=L_{m, p} / L_{r, p}, K \prime=L_{m, s} / L_{r, s}$ and $F=F^{\prime}=f_{s w} / f_{r}$. From Equations (11)-(13), one can observe three voltage gains have the same transfer function with different dc voltage values. Thus, the voltage gains of the proposed converter can be plotted in Figure 9.

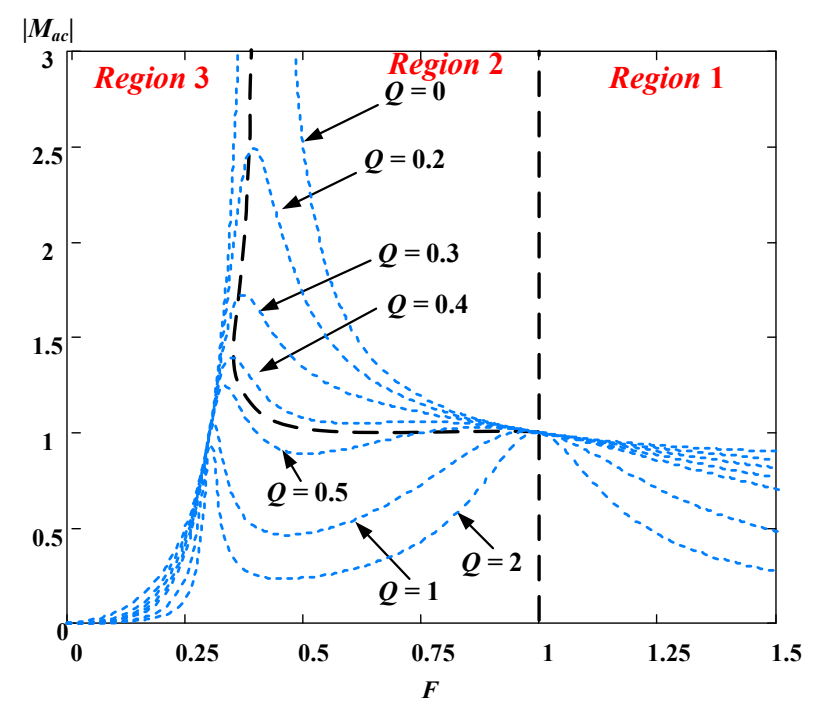

Figure 9. Voltage gains of the proposed converter.

\section{Prototype and Experimental Results}

The proposed circuit is implemented to demonstrate and verify the effectiveness of the studied circuit. The basic electric specifications are $V_{\text {in }}=100-400 \mathrm{~V}, V_{o}=48 \mathrm{~V}, P_{o}=1 \mathrm{~kW}$ and $f_{r}=100 \mathrm{kHz}$. When $V_{i n}=100-200 \mathrm{~V}$, the full bridge resonant circuit $\left(S_{5}\right.$ is off) is used on the primary side. If $V_{i n}=200-400 \mathrm{~V}$, the half bridge resonant circuit $\left(S_{5}\right.$ is on and $S_{3}$ and $S_{4}$ are off) is adopted on the left-hand side. For reverse power operation, the source voltage $\left(V_{o}\right)$ is from 42 to $48 \mathrm{~V}$ and the load voltage $\left(V_{\text {in }}\right)$ is controlled at $400 \mathrm{~V}$. From the voltage gain Equations (11)-(13), the reverse and forward power operations have a similar transfer function. Thus, the prototype circuit design is based on the forward power operation and low input voltage range $\left(V_{i n}=100-200 \mathrm{~V}\right)$. In order to make the design easier, the resonant components on the primary and secondary sides are assumed as $C_{r, p}=C_{r, s} / n^{2}$ and $L_{r, p}=n^{2} L_{r, s}$. First the turns ratio, $n$, is calculated at $V_{i n, \max }=200 \mathrm{~V}$. The minimum voltage gain $\left|M_{a c, F, L o w}\right|_{\text {min }}$ is set at 1 under $V_{\text {in, } \max }=200 \mathrm{~V}$ and $V_{o}=48 \mathrm{~V}$. The turn-ratio $n$ is obtained in Equation (14).

$$
n=\left|M_{a c, F, \text { Low }}\right|_{\min } \times \frac{V_{i n, \max }}{V_{o}}=1 \times \frac{200}{48}=4.166
$$

In the experimental circuit, the selected primary turns and secondary turns are 24 and 6 , respectively. Therefore, the transformer turns ratio becomes $n=24 / 6=4$. According to the selected turns ratio $n=4$, the proposed converter operated at a forward power 
operation under a low input voltage range has minimum and maximum voltage gains in Equations (15) and (16). Figure 10 gives the gain curves under the $K=5$ condition.

$$
\begin{aligned}
& \left|G_{a c, F, \text { Low }}\right|_{\min }=\frac{n V_{o}}{V_{i n, \max }}=\frac{4 \times 48}{200}=0.96 \\
& \left|G_{a c, F, \text { Low }}\right|_{\max }=\frac{n V_{o}}{V_{\text {in, } \min }}=\frac{4 \times 48}{100}=1.92
\end{aligned}
$$

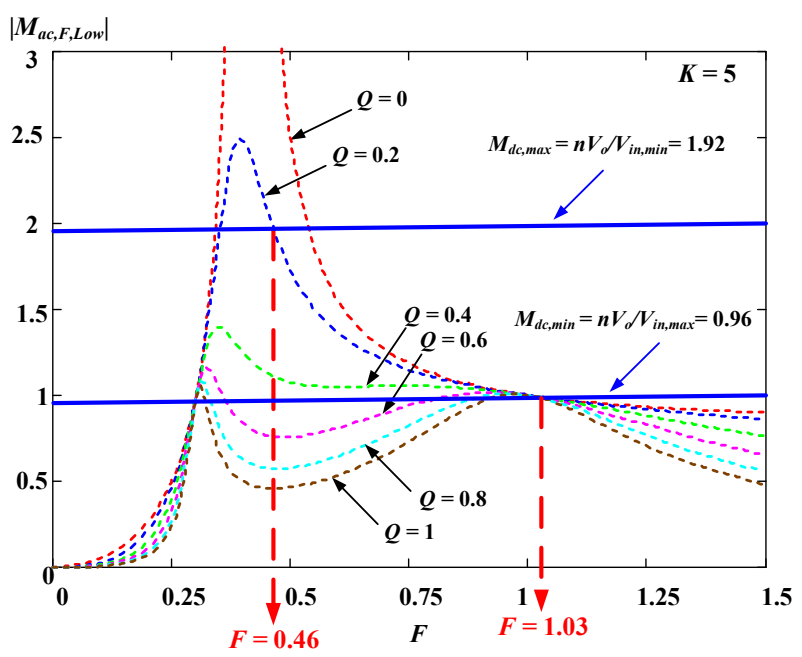

Figure 10. Gain curves of the prototype circuit under low input voltage range and forward power flow.

From the gain curves in Figure 10, one can observe the quality factor $Q<0.2$ can obtain the corresponding switching frequency index $F$ from $V_{\text {in, } \min }=100 \mathrm{~V}$ to $V_{\text {in, } \max }=200 \mathrm{~V}$. In this prototype circuit, $Q=0.2$ is selected and the switching frequency index can be obtained as $F=0.46$ under $V_{i n, \min }=100 \mathrm{~V}$ and $F=1.03$ under $V_{i n, \min }=200 \mathrm{~V}$. From Equation (3), $R_{o, a c}$ is calculated as follows:

$$
R_{o, a c}=\frac{8 n^{2} R_{o}}{\pi^{2}}=\frac{8 \times 4^{2} \times\left(48^{2} / 1000\right)}{3.14159^{2}} \approx 30 \Omega
$$

The resonant components can be obtained as follows:

$$
\begin{gathered}
L_{r, p}=Q R_{o, a c} /\left(2 \pi f_{r}\right) \approx 9.5 \mu \mathrm{H} \\
C_{r, p}=1 /\left(2 \pi Q f_{r} R_{o, a c}\right) \approx 265 \mathrm{nF} \\
L_{r, s}=L_{r, p} / n^{2} \approx 0.6 \mu \mathrm{H} \\
C_{r, s}=n^{2} C_{r, p} \approx 4.24 \mu \mathrm{F} \\
L_{m, p}=K L_{r, p} \approx 47.5 \mu \mathrm{H}
\end{gathered}
$$

Table 2 shows the circuit components used in the laboratory prototype. A voltage comparator with $V_{\text {ref }}=200 \mathrm{~V}$ is selected to achieve wide input voltage operation. If $V_{\text {in }}<$ or $>200 \mathrm{~V}$, then $S_{5}$ is OFF or ON. The frequency control analog integrated circuit such as UCC 25600 is used to generate the gate signals of $S_{1}-S_{4}$ and $Q_{1}-Q_{4}$. 
Table 2. Circuit Components in the laboratory prototype.

\begin{tabular}{cc}
\hline Items & Parameter \\
\hline Primary side split capacitances $C_{1}, C_{2}$ & $220 \mu \mathrm{F} / 400 \mathrm{~V}$ \\
\hline Primary side resonant capacitance $C_{r, p}$ & $265 \mathrm{nF}$ \\
\hline Primary side resonant inductance $L_{r, p}$ & $9.5 \mu \mathrm{H}$ \\
\hline Primary side magnetizing inductance $L_{m, p}$ & $47.5 \mu \mathrm{H}$ \\
\hline Primary side switches $S_{1}-S_{5}$ & GP50B60PD1 $(600 \mathrm{~V} / 33 \mathrm{~A})$ \\
\hline Secondary side resonant capacitance $C_{r, s}$ & $4.24 \mu \mathrm{F}$ \\
\hline Secondary side resonant inductance $L_{r, s}$ & $0.6 \mu \mathrm{H}$ \\
\hline Secondary side switches $Q_{1}-Q_{4}$ & IPP05CN10N G (100 V/100 A) \\
\hline Secondary output capacitance $C_{0}$ & $3000 \mu \mathrm{H} / 100 \mathrm{~V}$ \\
\hline Transformer $n_{p}: n_{\mathrm{s}}$ & $24: 6(\mathrm{PC} 40 \mathrm{EER} 42)$ \\
\hline
\end{tabular}

Figures 11-14 provide the measured waveforms of the proposed circuit under the forward power operation and Figure 15 gives the test results under the reverse power operation. The proposed converter is operated at a full bridge (or half bridge) resonant circuit when $V_{\text {in }}=100-200 \mathrm{~V}$ (or 200-400 V). To avoid the circuit variation between the full bridge and half bridge circuits at $V_{\text {in }}=200 \mathrm{~V}, \mathrm{a} \pm 2 \mathrm{~V}$ voltage tolerance is used to determine the low and high input voltage ranges. That means the full bridge (or half bridge) resonant circuit is used on the left-hand side of the proposed circuit under $V_{\text {in }}=100-202 \mathrm{~V}$ (or 198-400 V). Figures 11 and 12 shows the test waveforms of the proposed converter under full bridge resonant circuit operation at $V_{\text {in }}=100$ and 202 V, respectively. Figure 11a,b provide the measured PWM signals of $S_{1}-S_{4}$ under $20 \%$ and $100 \%$ loads at a $V_{\text {in }}=100 \mathrm{~V}$ input. Since the full bridge resonant circuit is used, $S_{5}$ is off. One can observe $S_{1}-S_{4}$ have lower switching frequencies at a $100 \%$ load than a $20 \%$ load. Figure $11 \mathrm{c}$, d provide the test results on the primary side and secondary side of the presented converter at the full load condition. From Figure 10, the proposed converter has a 1.92 voltage gain at $V_{\text {in }}=100 \mathrm{~V}$ and the switching frequency index $F \approx 0.47$. That means the switching frequency $f_{s w}$ is less than the series resonant frequency $f_{r}$. Therefore, power switches $S_{1}-S_{4}$ are operated at zero voltage switching and the synchronous switches $Q_{1}-Q_{4}$ are turned off zero current switching. The square waveform is generated on leg voltage $v_{a b}$. When $v_{a b}$ is a positive (or negative) voltage in Figure $11 \mathrm{c}, i_{L r, p}$ and $v_{C r, p}$ increase (or decrease). In Figure $11 \mathrm{~d}$, the voltage $v_{C r, s}$ becomes constant when $i_{L r, s}=0$. Similarly, the test results of the proposed converter operated at $V_{\text {in }}=202 \mathrm{~V}$ are provided in Figure 12. From Figure 10, one can observe that the proposed converter has a 0.96 voltage gain, and the switching frequency index is equal to 1.03. That means the switching frequency is greater than the series resonant frequency. Therefore, the waveforms $i_{L r, p}, v_{C r, p}, i_{L r, s}$ and $v_{C r, s}$ are quasi-sinusoidal signals in Figure 12c,d. Figures 13 and 14 show that the measured waveforms of the proposed converter operated at a half bridge resonant circuit and forward power flow operation under $V_{\text {in }}=198$ and $400 \mathrm{~V}$, respectively. Under a half bridge resonant circuit operation, switch $S_{5}$ is on and $S_{3}$ and $S_{4}$ are off. Power switches $S_{1}$ and $S_{2}$ are controlled by variable frequency modulation. Figure 13a,b give the gating signals of $S_{1}, S_{2}$ and $S_{5}$ under $20 \%$ and $100 \%$ loads at a $V_{\text {in }}=198 \mathrm{~V}$ input. Due to the fact that the voltage gain at $V_{\text {in }}=198 \mathrm{~V}$ is greater than unity, the switching frequency $f_{s w}>$ resonant frequency $f_{r}$ and the synchronous switches can be turned off at zero current switching in Figure 13d. Similarly, the test results of the proposed circuit at $V_{i n}=400 \mathrm{~V}$ input are provided in Figure 14. The switching frequency of the presented circuit at $V_{i n}=400 \mathrm{~V}$ input has a lower voltage gain than the $198 \mathrm{~V}$ input case and the switching frequency is greater than the series resonant frequency. The quasi-sinusoidal waveforms are measured on $i_{L r, p}, v_{C r, p}, i_{L r, s}$ and $v_{C r, s}$. Figure 15 gives the test results of the presented converter, operating at reverse power operation at $V_{i n}=400 \mathrm{~V}, V_{o}=48 \mathrm{~V}$ and a $100 \%$ load condition. The half bridge 
circuit is operated on the high voltage side. $Q_{1}-Q_{4}$ on the low voltage side are controlled as main power switches with variable frequency modulation and $S_{1}$ and $S_{2}$ on high voltage side are operated as the synchronous switches. Figure 15a,b show the PWM signals of $Q_{1}-Q_{4}$ at $20 \%$ and $100 \%$ loads. Figure $15 \mathrm{c}$ shows the waveforms $v_{d e}, i_{L r, s}$ and $v_{C r, s}$ on the low voltage side under a full load condition. Figure $15 \mathrm{~d}$ shows waveforms $i_{L r, p}, v_{C r, p}$ and $I_{0, \text { in }}$ on the high voltage side. Figure 16a-d give the PWM signals of $S_{1}$ for $V_{\text {in }}=100,198$, 202 and 400 V, respectively, under forward power operation. Similarly, Figure 16e provides the measured signals of $S_{1}$ under reverse power operation. From the measured results in Figure 16, one can observe that the power switch $S_{1}$ is turned on at zero voltage switching under the forward power operation and $Q_{1}$ is turned on at zero voltage switching under the reverse power operation. Figure 17 shows the PWM signals of $S_{3}-S_{5}$ under $V_{\text {in }}=100-400 \mathrm{~V}$. When $V_{\text {in }}$ is increased from 100 to $202 \mathrm{~V}$, the proposed converter is operated at a full bridge circuit structure. Therefore, $S_{5}$ is off and $S_{3}$ and $S_{4}$ are controlled with a variable frequency modulation. If $V_{\text {in }}$ is increased from 202 to $400 \mathrm{~V}$, the proposed converter is operated at a half bridge circuit structure. Thus, $S_{5}$ is on and $S_{3}$ and $S_{4}$ are off. The measured circuit efficiencies of the proposed converter are $92.7,91.5$ and $93.1 \%$ at 100, 198 and $400 \mathrm{~V}$ input and the full load condition.

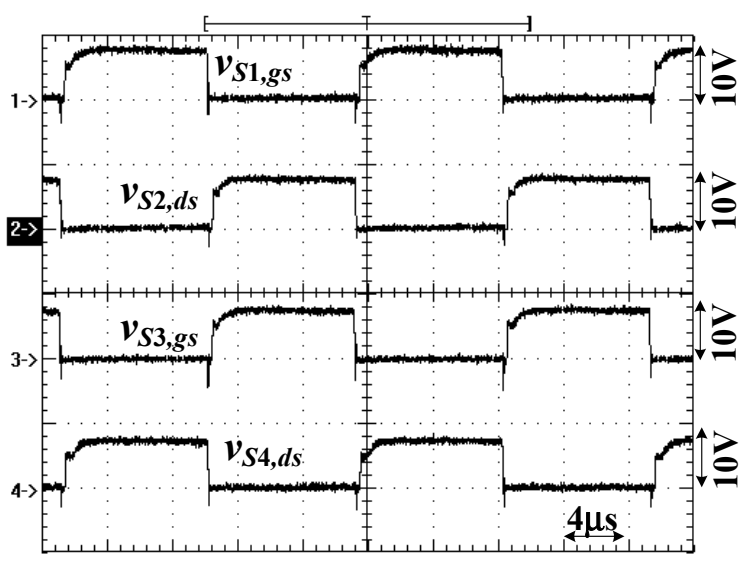

(a)

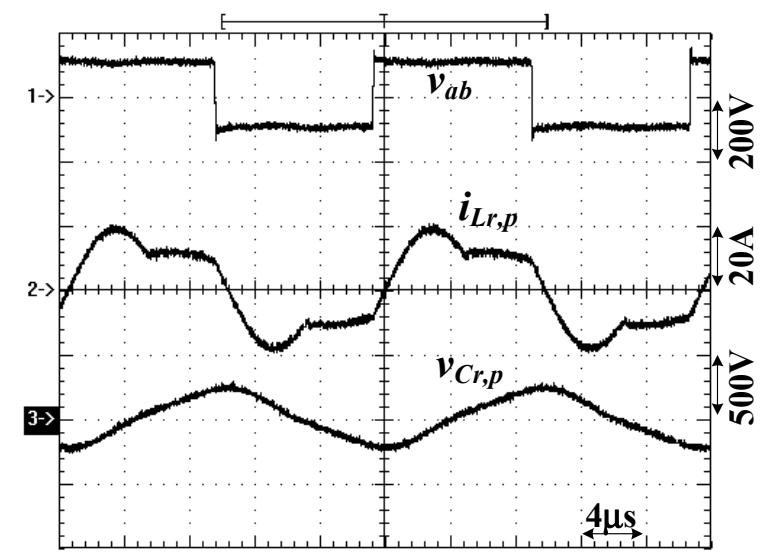

(c)

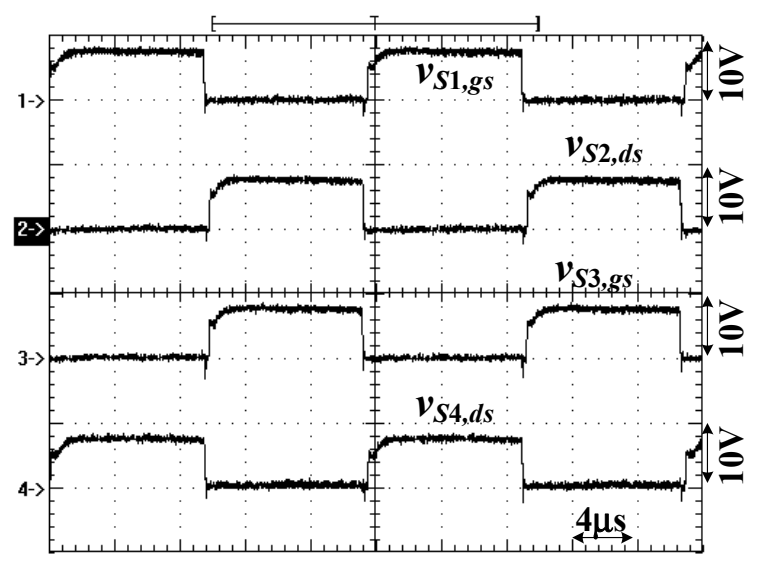

(b)

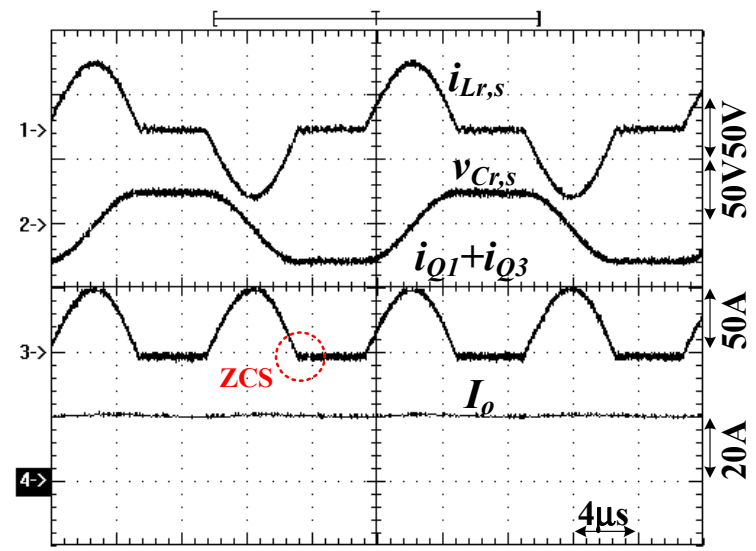

(d)

Figure 11. Measured waveforms of the proposed converter operated at forward power flow and $V_{\text {in }}=100 \mathrm{~V}:\left(\right.$ a) $S_{1}-S_{4}$ signals at $20 \%$ load power, (b) $S_{1}-S_{4}$ signals at $100 \%$ load power, (c) $v_{a b}, i_{L r, p}$ and $v_{C r, p}$ at full rated power, (d) $i_{L r, s}, v_{C r, s}, i_{Q 1}+i_{Q 3}$ and $I_{o}$ at full rated power. 


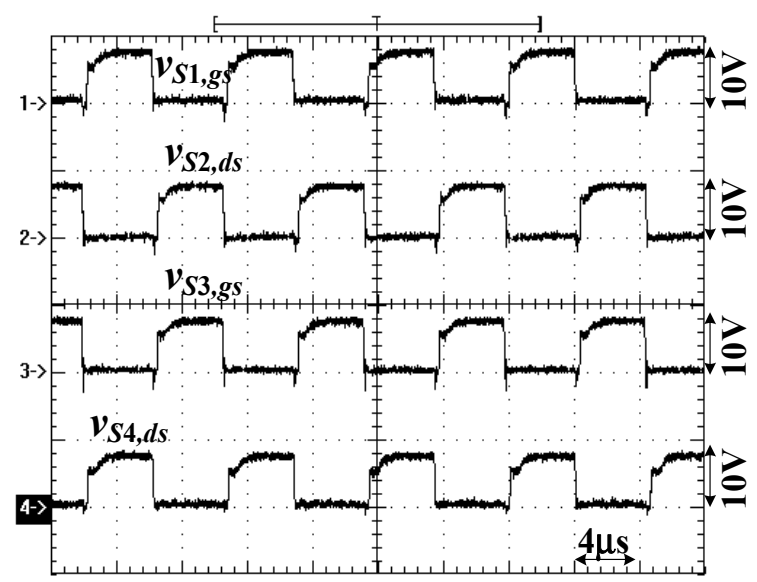

(a)

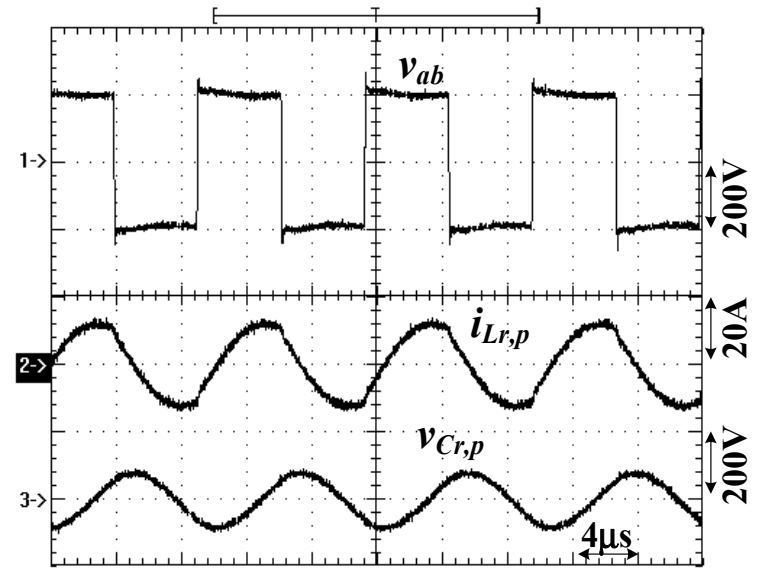

(c)

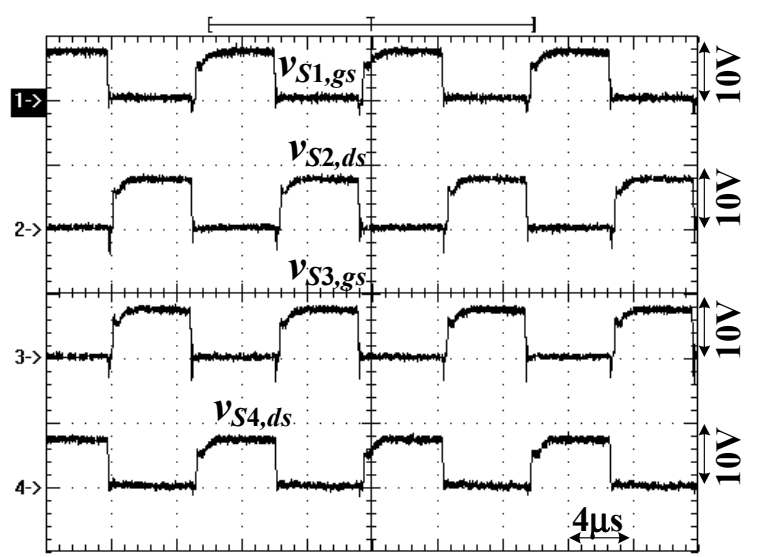

(b)

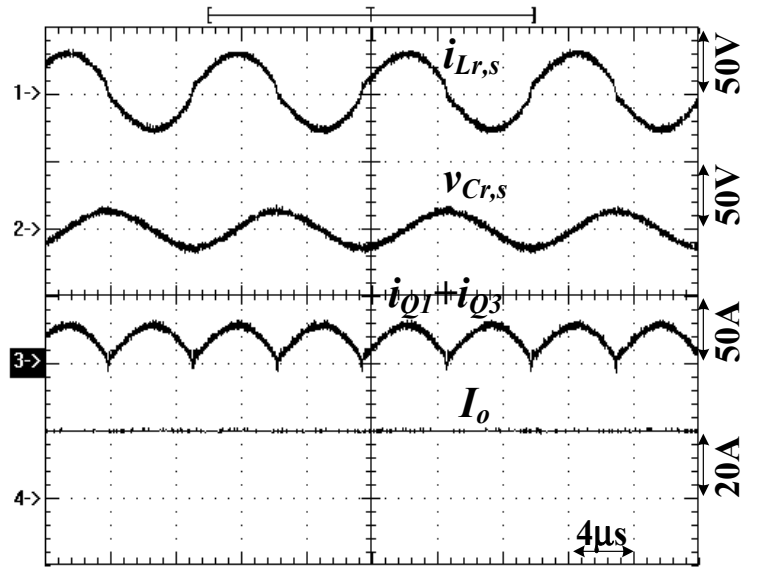

(d)

Figure 12. Measured waveforms of the proposed converter operated at forward power flow and $V_{\text {in }}=202 \mathrm{~V}:(\mathbf{a}) S_{1}-S_{4}$ signals at $20 \%$ load power, (b) $S_{1}-S_{4}$ signals at $100 \%$ load power, (c) $v_{a b}, i_{L r, p}$ and $v_{C r, p}$ at full rated power, (d) $i_{L r, s}, v_{C r, S}$ $i_{Q 1}+i_{Q 3}$ and $I_{0}$ at full rated power.

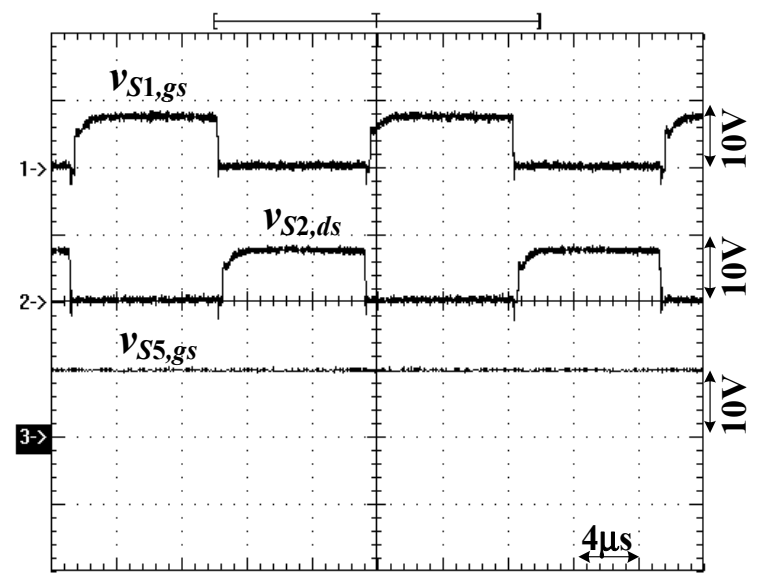

(a)

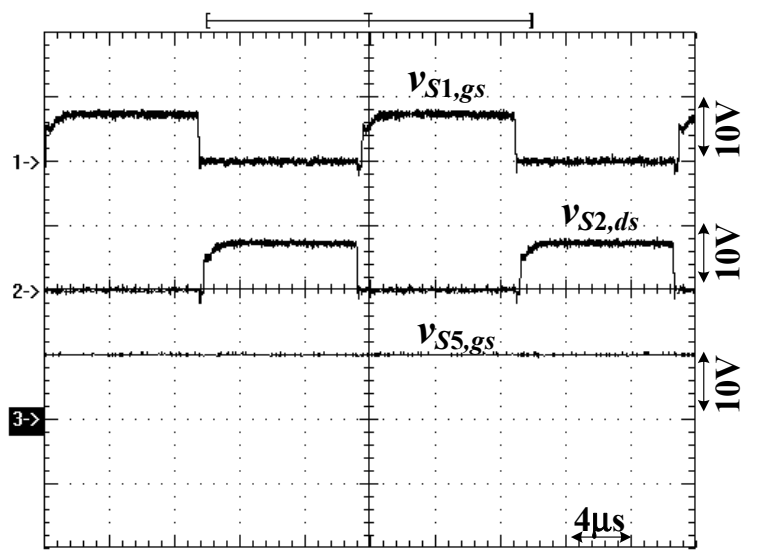

(b)

Figure 13. Cont. 


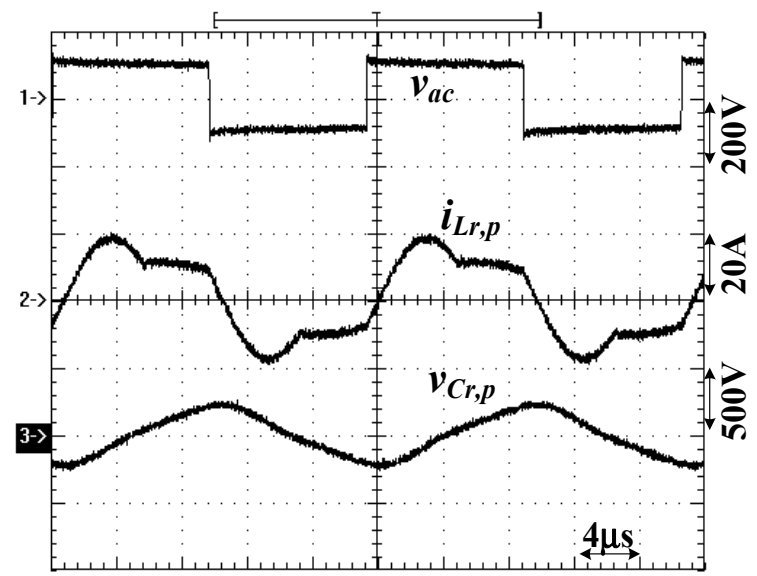

(c)

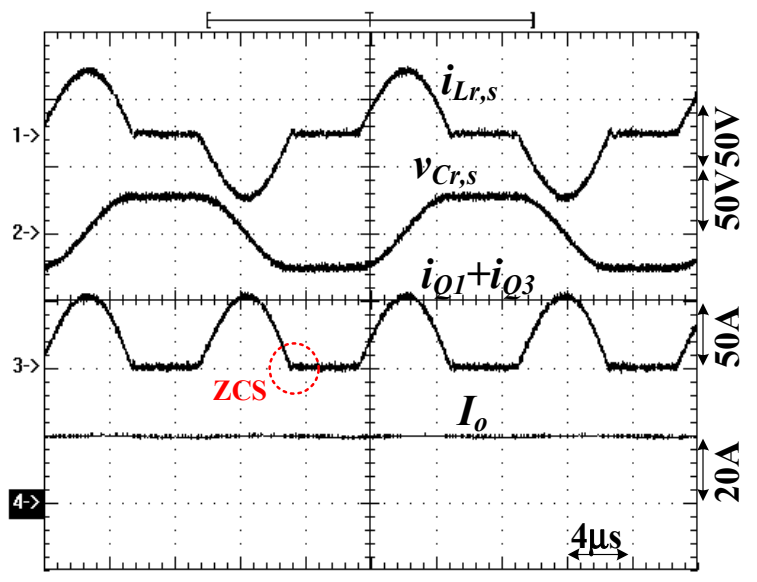

(d)

Figure 13. Measured waveforms of the proposed converter operated at forward power flow and $V_{\text {in }}=198 \mathrm{~V}$ : (a) $S_{1}, S_{2}$ and $S_{5}$ signals at $20 \%$ load power, (b) $S_{1}, S_{2}$ and $S_{5}$ signals at $100 \%$ load power, (c) $v_{a c}, i_{L r, p}$ and $v_{C r, p}$ at full rated power, (d) $i_{L r, s}, v_{C r, s}, i_{Q 1}+i_{Q 3}$ and $I_{O}$ at full rated power.

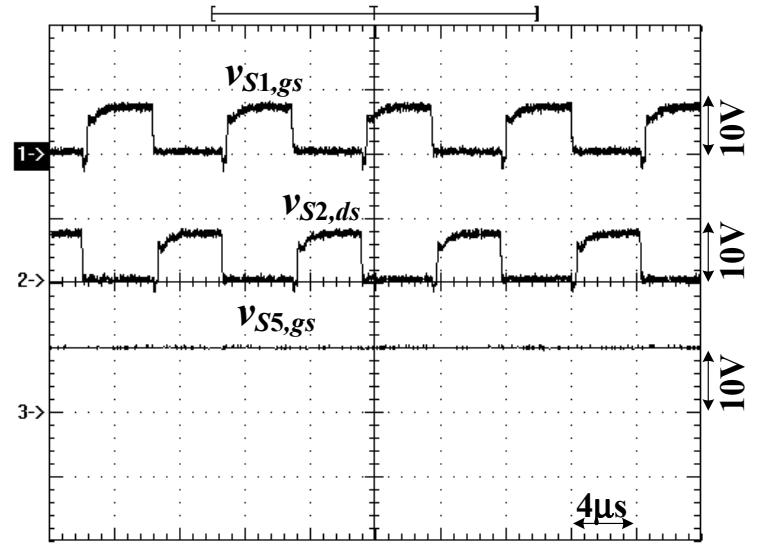

(a)

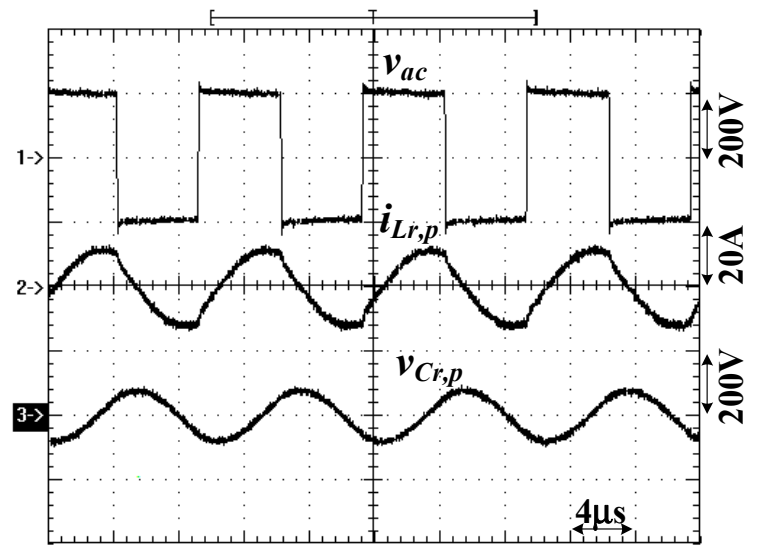

(c)

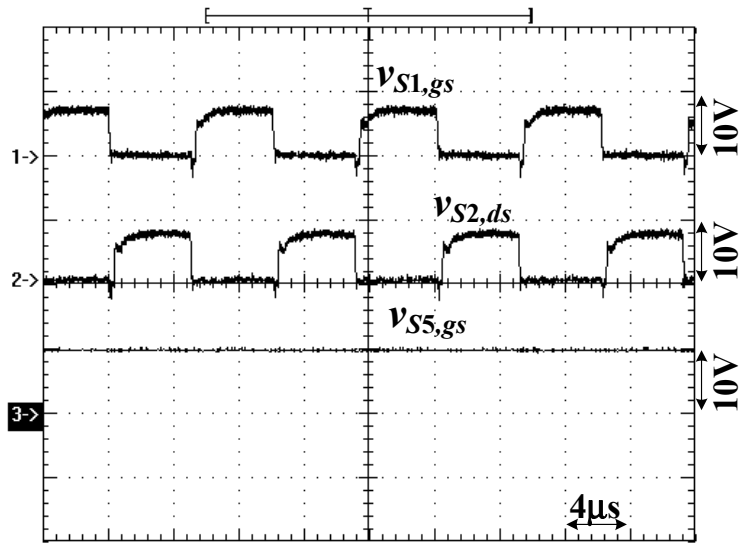

(b)

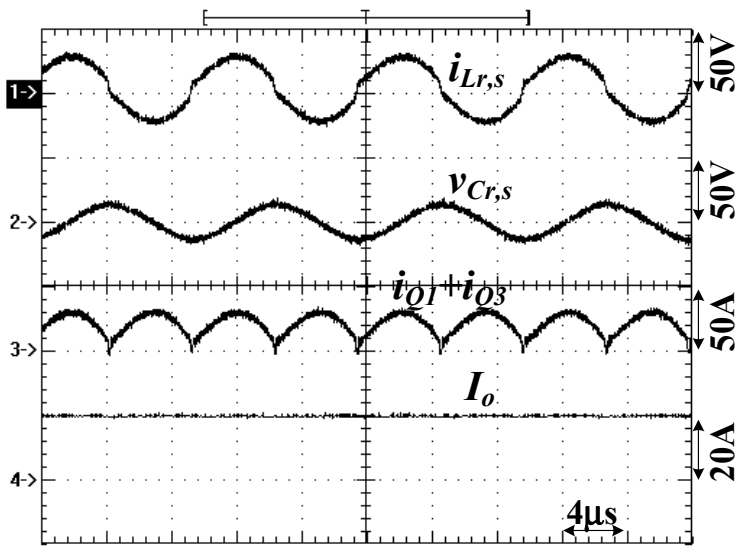

(d)

Figure 14. Measured waveforms of the proposed converter operated at forward power flow and $V_{\text {in }}=400 \mathrm{~V}:$ (a) $S_{1}, S_{2}$ and $S_{5}$ signals at $20 \%$ load power, (b) $S_{1}, S_{2}$ and $S_{5}$ signals at $100 \%$ load power, (c) $v_{a c}, i_{L r, p}$ and $v_{C r, p}$ at full rated power, (d) $i_{L r, S}$, $v_{C r, s}, i_{Q 1}+i_{Q 3}$ and $I_{0}$ at full rated power. 


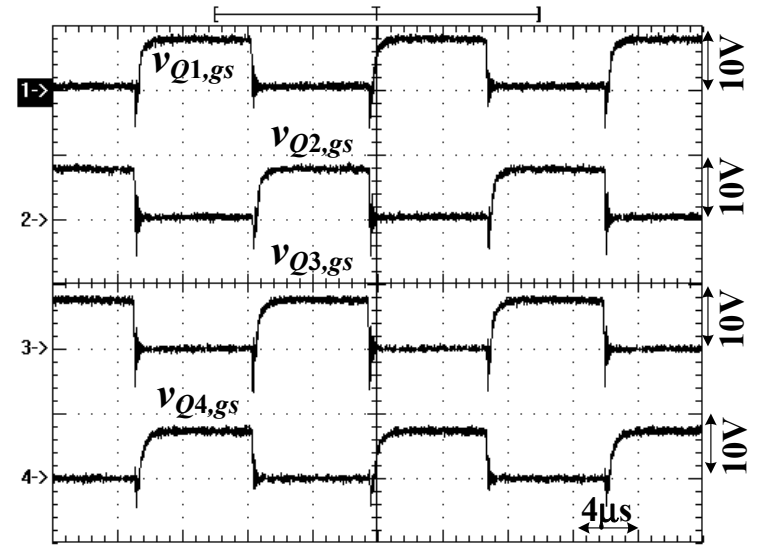

(a)

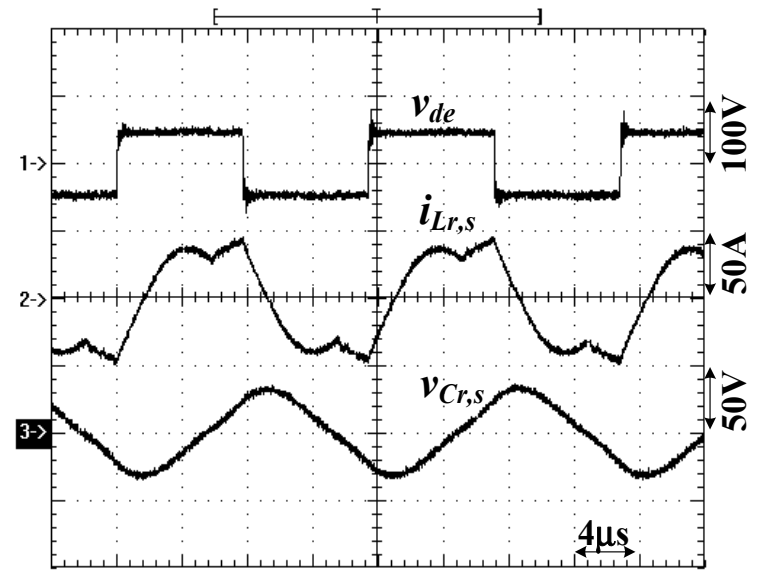

(c)

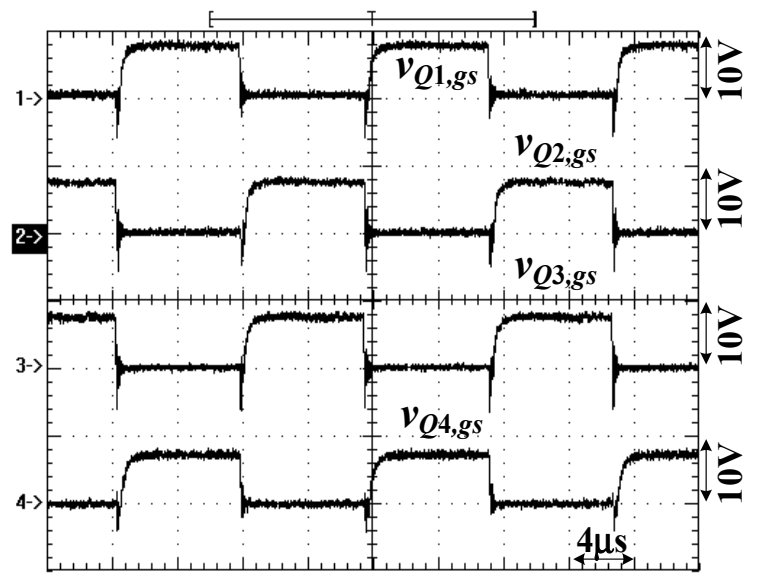

(b)

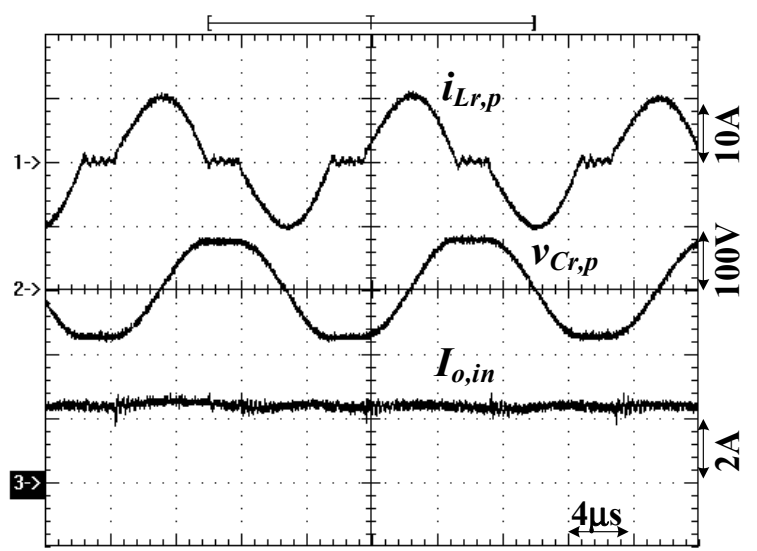

(d)

Figure 15. Measured waveforms of the proposed converter operated at reverse power flow: (a) $Q_{1}-Q_{4}$ signals at 20\% load power, (b) $Q_{1}-Q_{4}$ signals at $100 \%$ load power, (c) $v_{d e}, i_{L r, s}$ and $v_{C r, s}$ at full rated power, (d) $i_{L r, p}, v_{C r, p}$ and $I_{o, i n}$ at full rated power. 


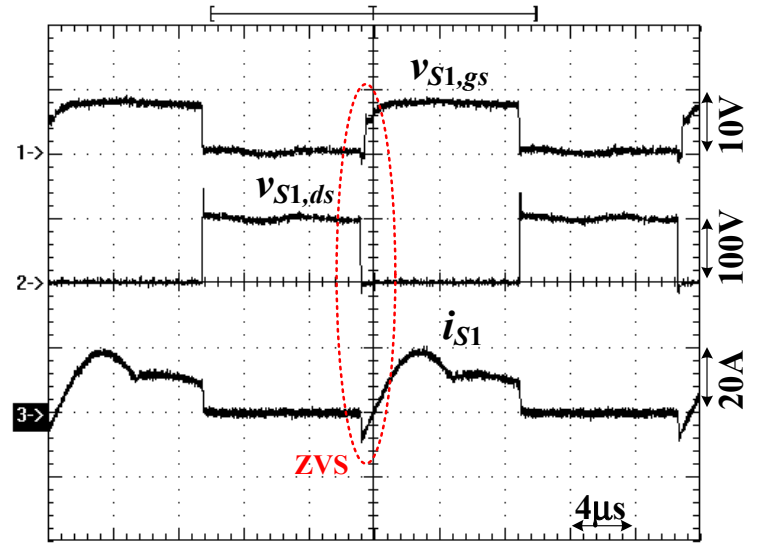

(a)

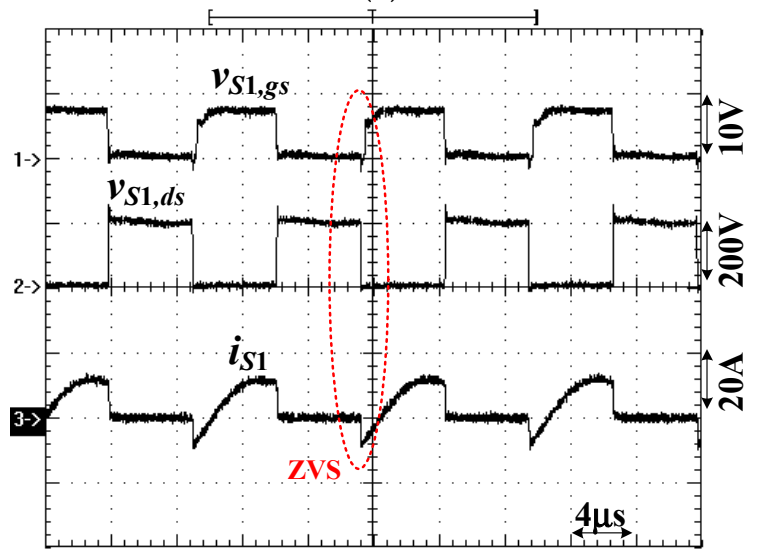

(c)

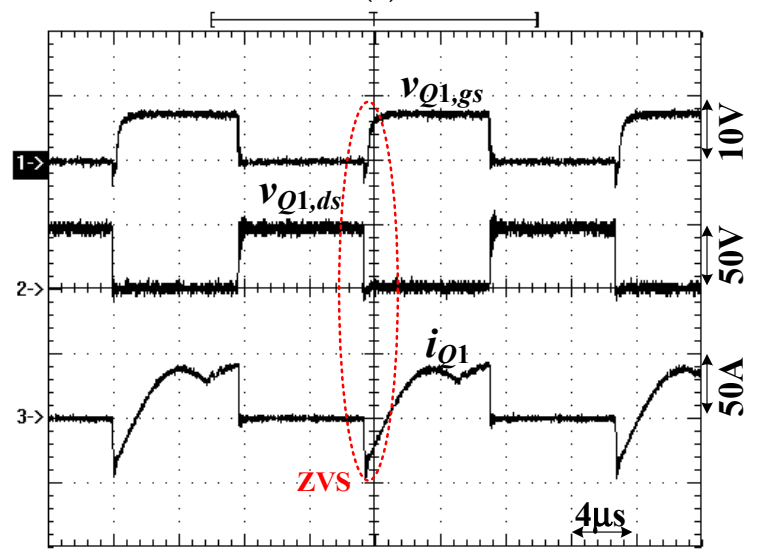

(e)

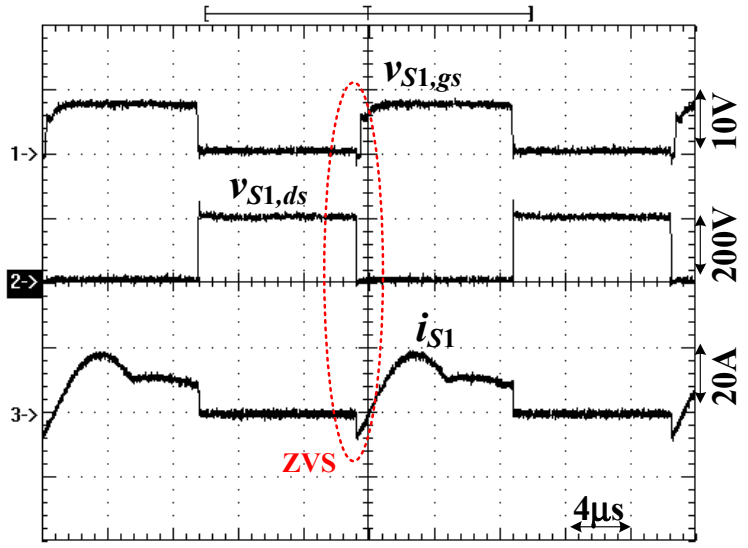

(b)

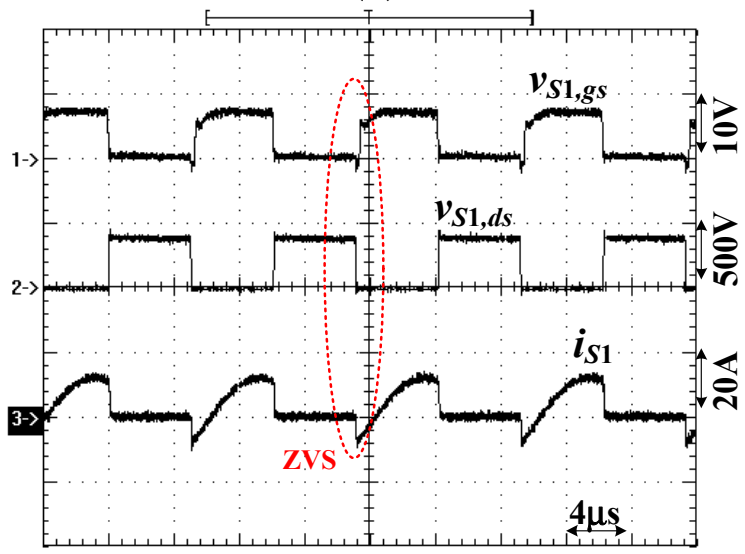

(d)

Figure 16. Measured switch waveforms at full load: (a) $S_{1}$ at $V_{\text {in }}=100 \mathrm{~V}$ and forward power operation, (b) $S_{1}$ at $V_{\text {in }}=198 \mathrm{~V}$ and forward power operation, (c) $S_{1}$ at $V_{\text {in }}=202 \mathrm{~V}$ and forward power operation, (d) $S_{1}$ at $V_{\text {in }}=400 \mathrm{~V}$ and forward power operation, (e) $Q_{1}$ at reverse power operation. 


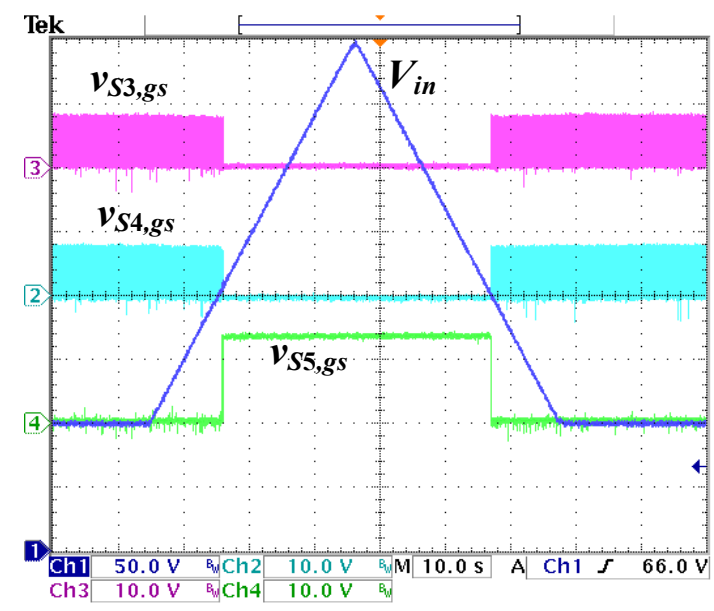

Figure 17. Measured waveforms of $S_{3}-S_{5}$ and $V_{\text {in }}$ between $V_{\text {in }}=100$ and $400 \mathrm{~V}$.

\section{Conclusions}

A wide voltage range DC converter with bidirectional power flow operation is presented, discussed and implemented for wide input voltage variation applications such as fuel cell and solar power conversion. The proposed converter can also be used for an electric vehicle charger between the DC nano-grid or micro-grid with $380 \mathrm{~V}$ DC bus voltage and electric vehicle high voltage battery stacks with $200-700 \mathrm{~V}$ battery voltage to achieve G2V (grid-to-vehicle) and V2G (vehicle-to-grid) operations. The symmetric resonant tank is used to achieve a bidirectional power operation. The resonant circuit is operated under a variable frequency modulation with an inductive load characteristic. Power switches can achieve a zero-voltage turn-on operation with less switching loss. According to the high or low input voltage range, half bridge or full bridge resonant structure is selected to achieve the low or high voltage gain of the presented circuit in order to control the load voltage. Compared to the conventional bidirectional resonant converters, the presented circuit can achieve a wide voltage range operation and a bidirectional zero voltage turn-on operation. Finally, the theoretical analysis of the presented bidirectional resonant circuit is confirmed by the experimental results.

Funding: This research is supported by the National Yunlin University of Science and Technology, Taiwan, under grant number $109 \mathrm{H} 500311$.

Acknowledgments: The author thanks the financial support by the National Yunlin University of Science and Technology, Taiwan, under grant number 109H500311. The author also likes to thank M.-C. Ko for his help to measure and validate the experimental waveforms.

Conflicts of Interest: The authors declare no conflict of interest.

\section{References}

1. Guerrero, J.M.; Loh, P.C.; Lee, T.L.; Chandorkar, M. Advanced control architectures for intelligent microgrids—Part II: Power quality, energy storage, and ac/dc microgrids. IEEE Trans. Ind. Electron. 2013, 60, 1263-1270. [CrossRef]

2. Meng, L.; Shafiee, Q.; Trecate, G.F.; Karimi, H.; Fulwani, D.; Lu, X.; Guerrero, J.M. Review on control of DC microgrids and multiple microgrid clusters. IEEE J. Emerg. Sel. Top. Power Electron. 2017, 5, 928-948.

3. Jing, W.; Lai, C.H.; Wong, S.H.W.; Wong, M.L.D. Battery-super capacitor hybrid energy storage system in standalone dc microgrids: A review. IET Renew. Power Gener. 2017, 11, 461-469. [CrossRef]

4. Emadi, A.; Lee, Y.J.; Rajashekara, K. Power electronics and motor drives in electric, hybrid electric, and plug-in hybrid electric vehicles. IEEE Trans. Ind. Electron. 2008, 55, 2237-2245. [CrossRef]

5. Mangu, B.; Akshatha, S.; Suryanarayana, D.; Fernandes, B.G. Grid-connected PV-wind-battery-based multi-input transformercouple bidirectional dc-dc converter for household applications. IEEE J. Emerg. Sel. Top. Power Electron. 2016, 4, 1086-1095. [CrossRef]

6. Yilmaz, M.; Krein, P.T. Review of battery charger topologies, charging power levels, and infrastructure for plug-in electric and hybrid vehicles. IEEE Trans. Power Electron. 2013, 28, 2151-2169. [CrossRef] 
7. Ahrabi, R.R.; Ardi, H.; Elmi, M.; Ajami, A. A novel step-up multi input dc-dc converter for hybrid electric vehicles application. IEEE Trans. Power Electron. 2017, 32, 3549-3561. [CrossRef]

8. Xu, D.; Zhao, C.; Fan, H. A PWM plus phase-shift control bidirectional DC-DC converter. IEEE Trans. Power Electron. 2004, 19, 666-675. [CrossRef]

9. Lara, J.; Masisi, L.; Hernandez, C.; Arjona, A.; Chandra, A. Novel five-level ANPC bidirectional converter for power quality enhancement during G2V/V2G operation of cascaded EV charger. Energies 2021, 14, 2650. [CrossRef]

10. Rico, S.J.; Pagano, D.J.; Lucas, K.E. Bidirectional power sharing for DC microgrid enabled by dual active bridge DC-DC converter. Energies 2021, 14, 404.

11. Jain, A.K.; Ayyanar, R. PWM control of dual active bridge: Comprehensive analysis and experimental verification. IEEE Trans. Power Electron. 2011, 26, 1215-1227. [CrossRef]

12. Zou, S.; Lu, J.; Mallik, A.; Khaligh, A. Bi-directional CLLC converter with synchronous rectification for plug-in electric vehicles. IEEE Trans. Ind. Appl. 2018, 54, 998-1005. [CrossRef]

13. Jung, J.H.; Kim, H.S.; Ryu, M.H.; Baek, J.W. Design methodology of bidirectional CLLC resonant converter for high-frequency isolation of DC distribution systems. IEEE Trans. Power Electron. 2013, 28, 1741-1755. [CrossRef]

14. Liu, Y.; Du, G.; Wang, X.; Lei, Y. Analysis and design of high-efficiency bidirectional GaN-based CLLC resonant converter. Energies 2019, 12, 3859. [CrossRef] 